\title{
Classifying Induced Superconductivity in Atomically Thin Dirac-Cone Materials
}

\author{
Evgueni F. Talantsev ${ }^{1,2}$ (1) \\ 1 M. N. Miheev Institute of Metal Physics, Ural Branch, Russian Academy of Sciences, 18, S. Kovalevskoy St., \\ Ekaterinburg 620108, Russia; evgeny.talantsev@imp.uran.ru; Tel.: +7-912-676-0374 \\ 2 NANOTECH Centre, Ural Federal University, 19 Mira St., Ekaterinburg 620002, Russia
}

Received: 19 August 2019; Accepted: 16 September 2019; Published: 18 September 2019

\begin{abstract}
Recently, Kayyalha et al. (Phys. Rev. Lett., 2019, 122, 047003) reported on the anomalous enhancement of the self-field critical currents $\left(I_{c}(s f, T)\right.$ ) at low temperatures in $\mathrm{Nb} / \mathrm{BiSbTeSe}_{2}-$ nanoribbon/ $/ \mathrm{Nb}$ Josephson junctions. The enhancement was attributed to the low-energy Andreev-bound states arising from the winding of the electronic wave function around the circumference of the topological insulator BiSbTeSe ${ }_{2}$ nanoribbon. It should be noted that identical enhancement in $I_{\mathrm{c}}(\mathrm{sf}, T)$ and in the upper critical field $\left(B_{\mathrm{c} 2}(T)\right)$ in approximately the same reduced temperatures, were reported by several research groups in atomically thin junctions based on a variety of Dirac-cone materials (DCM) earlier. The analysis shows that in all these $\mathrm{S} / \mathrm{DCM} / \mathrm{S}$ systems, the enhancement is due to a new superconducting band opening. Taking into account that several intrinsic superconductors also exhibit the effect of new superconducting band(s) opening when sample thickness becomes thinner than the out-of-plane coherence length $\left(\xi_{c}(0)\right)$, we reaffirm our previous proposal that there is a new phenomenon of additional superconducting band(s) opening in atomically thin films.
\end{abstract}

Keywords: superconductivity enhancement in atomically thin films; Dirac-cone materials; single layer graphene; Josephson junctions; multiple-band superconductivity

\section{Introduction}

Intrinsic superconductors can be grouped into 32 classes under "conventional", "possibly unconventional", and "unconventional" categories, according to the mechanism believed to give rise to superconductivity [1]. One of the most widely used concepts to represent all 32 classes of superconductors was proposed by Uemura et al. [2,3]. The concept of the Uemura plot is based on the utilization of two fundamental temperatures of superconductors: one is the Fermi temperature $\left(T_{\mathrm{F}}\right)$ ( $X$-axis), and the superconducting transition temperature $\left(T_{\mathrm{c}}\right)(Y$-axis). In the most recently updated Uemura plot (Figure 1), it can be seen that elemental superconductors are located for wide range of $T_{\mathrm{C}} / T_{\mathrm{F}} \leq 0.001$, while all unconventional superconductors, including both nearly-room-temperature superconductors of $\mathrm{H}_{3} \mathrm{~S}$ [4] and $\mathrm{LaH}_{10}$ [5] (for which experimentally measured upper critical field data [6,7] was analyzed in Refs. [8,9]), are located within a narrow band of $0.01 \leq T_{\mathrm{C}} / T_{\mathrm{F}} \leq 0.05$.

It should be mentioned that Hardy et al. [10] in 1993 (seven years after the discovery of high-temperature superconductivity in cuprates by Bednoltz and Mueller [11]) were the first to experimentally find that $\mathrm{YBa}_{2} \mathrm{Cu}_{2} \mathrm{O}_{7-\mathrm{x}}$ has nodal superconducting gap. This experimental result was used to propose $d$-wave superconducting gap symmetry in HTS cuprates by Won and Maki [12]. It should be noted that several researchers and research groups (over last 33 years) have proposed different mechanisms for high-temperature superconductivity in cuprates, the first two-band BCS superconductor $\left(\mathrm{MgB}_{2}\right)$, pnictides, and hydrogen-rich superconductors, for which we refer the reader to original papers and comprehensive reviews [13-31]. 


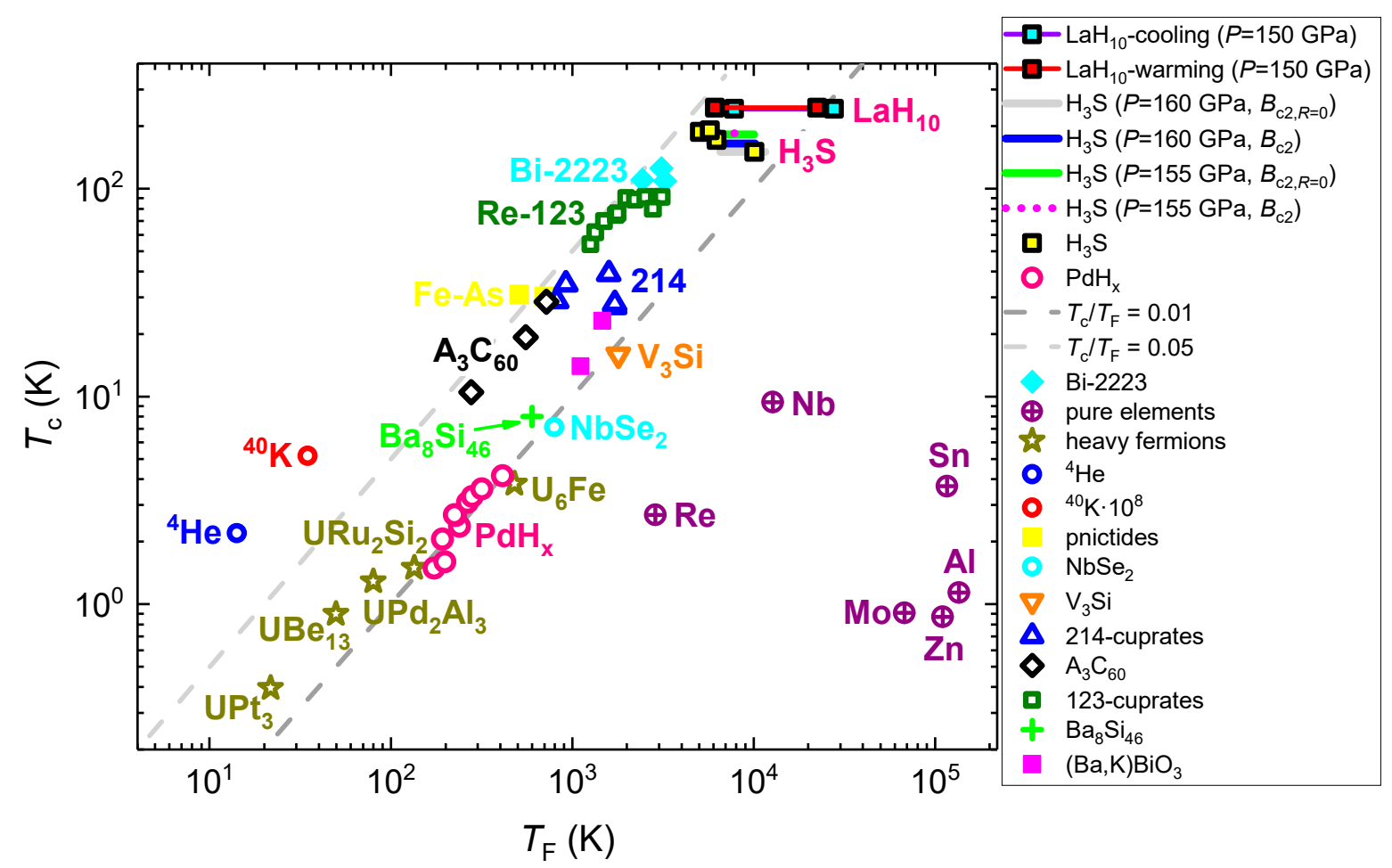

Figure 1. A plot of superconducting transition temperature $\left(T_{\mathrm{C}}\right)$ versus Fermi temperature $\left(T_{\mathrm{F}}\right)$ obtained for most representative superconducting families. Data was taken from [3,8,9,32-35].

Despite some differences, all intrinsic superconductors can induce superconducting state in non-superconducting materials via the Holm-Meissner effect [36] (also designated as the proximity effect $[37,38]$ ). As direct consequence of this, non-dissipative transport current can flow throw the non-superconducting material at superconductor/non-superconductor/superconductor $(\mathrm{S} / \mathrm{N} / \mathrm{S})$ junctions. The amplitude of this non-dissipative transport current at self-field conditions (when no external magnetic field is applied) $\left(I_{\mathrm{C}}(\mathrm{sf}, T)\right)$ was given by Ambegaokar and Baratoff $(\mathrm{AB})[39,40]$ :

$$
I_{c}(s f, T)=\frac{\pi \Delta(T)}{2 e R_{n}} \tanh \left(\frac{\Delta(T)}{2 k_{B} T}\right)
$$

where $\Delta(T)$ is the temperature-dependent superconducting gap, $e$ is the electron charge, normal-state tunneling resistance $\left(R_{\mathrm{n}}\right)$ is the normal-state tunneling resistance in the junction, and $k_{\mathrm{B}}$ is the Boltzmann constant.

Many interesting physical effects are expected if the non-superconducting part of the S/N/S junction is made of single-layer graphene (SLG) [41]; multiple-layer graphene (MLG) [42]; graphene-like materials [43]; and many other new 2D- and nano-DCMs, which are under on-going discovery/invention/ exploration [44-73]. One interesting class of $\mathrm{S} / \mathrm{N} / \mathrm{S}$ junctions is the non-superconducting part of the device made of topological insulators (TI) [74-81]. Temperature-dependent self-field critical currents $\left(I_{c}(s f, T)\right)$ in this class of junctions were first reported by Veldhorst et al. in $\mathrm{Nb} / \mathrm{Bi}_{2} \mathrm{Te}_{3} / \mathrm{Nb}$ [52], and later by Kurter et al. in $\mathrm{Nb} / \mathrm{Bi}_{2} \mathrm{Se}_{3} / \mathrm{Nb}$ [53], by Charpentier et al. in $\mathrm{Al} / \mathrm{Bi}_{2} \mathrm{Te}_{3} / \mathrm{Al}$ [76], and by other research groups in different systems (extended reference list for studied S/TI/S junctions can be found in Refs. [79,80]).

Recently, Kayyalha et al. [82] have reported on anomalous enhancement of $I_{\mathrm{C}}(\mathrm{sf}, T)$ at the $\mathrm{Nb} / \mathrm{BiSbTeSe}_{2}$-nanoribon/ $\mathrm{Nb}$ junction at temperatures of $T \leq 0.25 T_{\mathrm{c}}$. They confirmed the effect in all five studied junctions [82], for which TI parts were made of $\mathrm{BiSbTeSe}_{2}$ flakes with thicknesses of $2 b$, which varied from $30 \mathrm{~nm}$ to $50 \mathrm{~nm}$, and flakes widths of $2 a$, which varied from $266 \mathrm{~nm}$ to $390 \mathrm{~nm}$. It should be noted that in all these S/TI/S junctions, BiSbTeSe $e_{2}$-nanoribbons thicknesses and widths 
were smaller than the ground state superconducting coherence length $(2 b<<2 a<\xi(0) \sim 600 \mathrm{~nm})$ in these devices [82]. For one junction, made of wider BiSbTeSe ${ }_{2}$-nanoribon $(2 a=4 \mu \mathrm{m}$ (Figure S4 of Supplementary Information of Ref. [82])), measurements were performed only at low temperatures $\left(T<2 \mathrm{~K}\right.$, which is about $T<0.2 T_{\mathrm{c}}$ (taking into account that $\mathrm{Nb}$ has $T_{\mathrm{c}}=8.9-9.6 \mathrm{~K}$ [83])), and thus more experimental studies are required for this $4-\mu \mathrm{m}$ wide $\mathrm{Nb} / \mathrm{BiSbTeSe}_{2}$-nanoribon/ $\mathrm{Nb}$ junction to see the $I_{\mathrm{c}}(\mathrm{sf}, T)$ enhancement.

It needs to be stressed that identical $I_{\mathrm{c}}(\mathrm{sf}, T)$ enhancement (or, in another words, $I_{\mathrm{c}}(\mathrm{sf}, T)$ upturn [46]) at approximately the same reduced temperature of $T \leq 0.25 T_{\mathrm{c}}$ in atomically-thin $\mathrm{S} / \mathrm{N} / \mathrm{S}$ junction was first reported by Calado et al. [46] in MoRe/SLG/MoRe junction in 2015. One year later, less prominent $I_{\mathrm{c}}(\mathrm{sf}, T)$ enhancement (which wass, however, still very clearly visible in raw experimental data [84]) in nominally the same MoRe/SLG/MoRe junctions at $T \leq 0.25 T_{\mathrm{c}}$ was reported by Borzenets et al. [49]. Based on this, it would be incorrect to attribute the $I_{\mathrm{c}}(\mathrm{sf}, T)$ enhancement at low reduced temperatures in $\mathrm{Nb} / \mathrm{BiSbTeSe}_{2}$-nanoribon/Nb [82] to unique property of $\mathrm{S} / \mathrm{TI} / \mathrm{S}$ junctions.

In addition, it is important to mention that Kurter et al. [53] were the first to report $I_{\mathrm{C}}(\mathrm{sf}, T)$ enhancement at the S/TI/S junction at a reduced temperature of $T \leq 0.25 T_{\mathrm{c}}$. At $\mathrm{Nb} / \mathrm{Bi}_{2} \mathrm{Se}_{3} / \mathrm{Nb}$ junctions, $\mathrm{Bi}_{2} \mathrm{Se}_{3}$ flake had a thickness of $2 b=9 \mathrm{~nm}$, and, thus, the condition of $2 b<\xi_{\mathrm{c}}(0)$ was also satisfied.

Overall, both S/TI/S [53,82], as S/SLG/S [46,49], studied junctions, for which the effect of the low-temperature $I_{\mathrm{C}}(\mathrm{sf}, T)$ enhancement was observed to have non-superconducting parts thinner than the ground state out-of-plane coherence lengths, $\xi_{c}(0)$. SLG thickness is $2 b=0.4-1.7 \mathrm{~nm}$ [84], and thus the condition of $2 b<<\xi_{c}(0)$ satisfies any SLG-based junctions.

It should be noted that several intrinsic superconductors exhibit multiple-band superconducting gapping $[85,86]$ and the enhancement of the transition temperature [87-93] when the condition of $2 b<\xi_{\mathrm{c}}(0)[86]$ is satisfied. The first discovered material in this class of superconductors is atomically thin FeSe [88-90], in which a 13-fold increase (i.e., $100 \mathrm{~K}$ vs $7.5 \mathrm{~K}$ ) is experimentally registered. Another milestone experimental finding in this field was reported by Liao et al. [43], who observed the effect of new superconducting band opening and $T_{\mathrm{c}}$ enhancement in few layers of stanene (which is the closest counterpart of graphene) by tuning the films' thicknesses. To date, maximal $T_{\mathrm{c}}$ increase due to the effect [86] stands with another single-atomic layer superconductor, $T_{d}-M_{0} e_{2}$, for which Rhodes et al. [93] reported a 30-fold $T_{\mathrm{C}}$ increase when samples were thinneed down to a single atomic layer.

This paper reports the results of an analysis of $I_{\mathrm{c}}(\mathrm{sf}, \mathrm{T})$ in $\mathrm{Nb} / \mathrm{BiSbTeSe}_{2}$-nanoribbon/ $\mathrm{Nb}$ [82] and $\mathrm{Nb} /\left(\mathrm{Bi}_{0.06} \mathrm{Sb}_{0.94}\right)_{2} \mathrm{Te}_{3} / \mathrm{Nb}$ [94] junctions, and of the upper critical field $\left(B_{\mathrm{c} 2}(T)\right)$ in $\mathrm{Sn} /$ single-layer graphene (SLG)/Sn junctions [95]. In the results, it is shown that a new superconducting band opening phenomenon in atomically thin superconductors, which we proposed earlier $[85,86]$, has further experimental support.

\section{Models Description}

In [85], it was proposed to substitute $\Delta(T)$ in Equation (1) by analytical expression given by Gross et al. [96], as follows:

$$
\Delta(T)=\Delta(0) \tanh \left(\frac{\pi k_{B} T_{c}}{\Delta(0)} \sqrt{\eta\left(\frac{\Delta C}{C}\right)\left(\frac{T_{C}}{T}-1\right)}\right)
$$

where $\Delta(0)$ is the ground-state amplitude of the superconducting band, $\Delta C / C$ is the relative jump in electronic specific heat at the $T_{\mathrm{c}}$, and $\eta=2 / 3$ for $s$-wave superconductors [96]. In result, $T_{\mathrm{c}}, \Delta C / C, \Delta(0)$, and $R_{\mathrm{n}}$ of the $\mathrm{S} / \mathrm{N} / \mathrm{S}$ junction can be deduced by fitting experimental of an $I_{\mathrm{c}}(\mathrm{sf}, T)$ dataset to Equation (1) (full expression for Equation (1) is given in Ref. [85]). 
In [85], it was shown that $\mathrm{S} / \mathrm{SLG} / \mathrm{S}$ and $\mathrm{S} / \mathrm{Bi}_{2} \mathrm{Se}_{3} / \mathrm{S}$ junctions exhibit two-decoupled band superconducting state, for which, for general case of multiple-decoupled bands, $I_{\mathrm{C}}(\mathrm{sf}, T)$ can be described by the following equation:

$$
I_{\mathcal{C}}(s f, T)=\sum_{i=1}^{N} \frac{\pi \Delta_{i}(T)}{2 e R_{n, i}} \theta\left(T_{c, i}-T\right) \tanh \left(\frac{\Delta_{i}(T)}{2 k_{B} T}\right),
$$

where the subscript $i$ refers to the $i$-band, $\theta(x)$ is the Heaviside step function, and each band has its own independent parameters of $T_{\mathrm{c}, i}, \Delta C_{i} / C_{i}, \Delta_{i}(0)$, and $R_{\mathrm{n}, i}$.

It should be noted that multiple-band induced superconductivity in junctions should be detectable by any technique which is sensitive to additional bands crossing the Fermi surface, for instance multiple distinct gaps should be evident in the temperature-dependence of the upper critical field, $B_{\mathrm{c} 2}(T)$, for which general equation is:

$$
B_{c 2}(T)=\sum_{i=1}^{N} B_{c 2, i}(T) \theta\left(T_{c, i}-T\right),
$$

where, within each $i$-band, the upper critical field can be described by known model. In this paper, four $B_{\mathrm{c} 2}(T)$ models were used to show that main result is model-independent. For instance, the following was used:

1. Two-fluid Gorter-Casimir (GC) model [97,98], as follows:

$$
B_{c 2}(T)=\sum_{i=1}^{N}\left[B_{c 2, i}(0)\left(1-\left(\frac{T}{T_{c, i}}\right)^{2}\right) \theta\left(T_{c, i}-T\right)\right]=\frac{\phi_{0}}{2 \pi} \sum_{i=1}^{N}\left[\frac{\theta\left(T_{c, i}-T\right)}{\xi_{i}^{2}(0)}\left(1-\left(\frac{T}{T_{c, i}}\right)^{2}\right)\right],
$$

where $\varphi_{0}=2.068 \times 10^{-15} \mathrm{~Wb}$ is flux quantum and $\xi_{i}(0)$ is the ground state in-plane coherence length of the $i$-band. This model is widely used for single-band superconductors ranging from 3D near-room-temperature superconducting hydrides $[4,7-9,99,100]$ to $2 \mathrm{D}$ superconductors $[88,89,95,101]$.

2. Jones-Hulm-Chandrasekhar (JHC) model [102], as follows:

$$
B_{c 2}(T)=\frac{\phi_{0}}{2 \pi} \sum_{i=1}^{N} \frac{\theta\left(T_{c, i}-T\right)}{\xi_{i}^{2}(0)}\left(\frac{1-\left(\frac{T}{T_{c, i}}\right)^{2}}{1+\left(\frac{T}{T_{c, i}}\right)^{2}}\right)
$$

3. Werthamer-Helfand-Hohenberg model $[103,104]$, for which we use analytical expression given by Baumgartner et al. [105] (we will designate this model as B-WHH herein), as follows:

$$
B_{c 2}(T)=\frac{\phi_{0}}{2 \pi} \sum_{i=1}^{N} \frac{\theta\left(T_{c, i}-T\right)}{\xi_{i}^{2}(0)}\left(\frac{\left(1-\frac{T}{T_{c, i}}\right)-0.153\left(1-\frac{T}{T_{c, i}}\right)^{2}-0.152\left(1-\frac{T}{T_{c, i}}\right)^{4}}{0.693}\right),
$$

4. Gor'kov model [106], for which simple analytical expression was given by Jones et al. [102], as follows:

$$
B_{c 2}(T)=\frac{\phi_{0}}{2 \pi} \sum_{i=1}^{N} \frac{\theta\left(T_{c, i}-T\right)}{\xi_{i}^{2}(0)}\left(\left(\frac{1.77-0.43\left(\frac{T}{T_{c, i}}\right)^{2}+0.07\left(\frac{T}{T_{c, i}}\right)^{4}}{1.77}\right)\left[1-\left(\frac{T}{T_{c, i}}\right)^{2}\right]\right),
$$




\section{Results}

\subsection{Planar Sn/SLG/Sn Array}

Superconductivity in planar graphene junctions varies by the change of the charge carrier density when it moves away from the Dirac point in the dispersion $[46,47,51]$. This change is usually controlled by the gate voltage $\left(V_{\mathrm{g}}\right)$ that applies to the junction. Han et al. [95] reported on a proximity-coupled array of Sn discs with diameter of $400 \mathrm{~nm}$ on SLG that were placed in a hexagonal lattice separated by $1 \mu \mathrm{m}$ between disks centers.

In Figures 2 and 3, we show reported $B_{\mathrm{c} 2}(T)$ for Sn/SLG/Sn array by Han et al. [95] in their Figures 4 and 5 at gate voltage of $V_{\mathrm{g}}=30 \mathrm{~V}$. We defined $B_{\mathrm{c} 2}(T)$ by two criteria of $R=0.01 \mathrm{k} \Omega$ (Figure 2) and $R=0.2 \mathrm{k} \Omega$ (Figure 3). It can be seen that there is an obvious upturn in $B_{\mathrm{c} 2}(T)$ at $T \leq 0.4 T_{\mathrm{c}}$, independent of the upper critical field definition criterion. It should be noted that the upturn occurs at practically the same reduced temperature at which Borzenets et al. [49] observed the $I_{\mathrm{C}}(\mathrm{sf}, T)$ enhancement in MoRe/SLG/MoRe junctions.

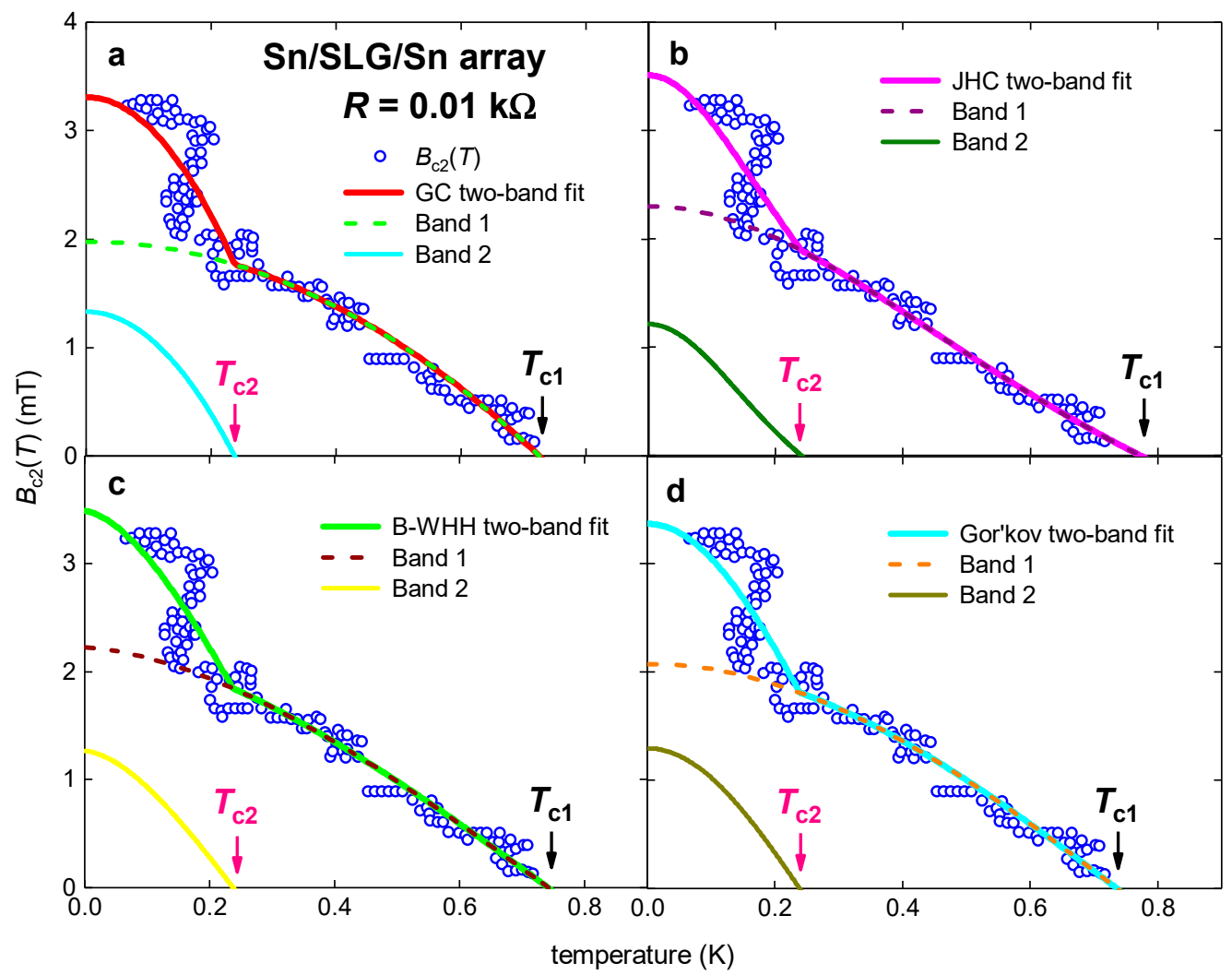

Figure 2. Experimental upper critical field $\left(B_{\mathrm{c} 2}(T)\right)$ for $\mathrm{Sn} /$ single-layer graphene (SLG)/Sn array at gate voltage of $V_{\mathrm{g}}=30 \mathrm{~V}$ [95] and data fits to Equations (5)-(8). $B_{\mathrm{c} 2}$ criterion is $R=0.01 \mathrm{k} \Omega$. (a) Gorter-Casimir (GC) model. Derived parameters are as follows: $T_{\mathrm{c} 1}=0.72 \pm 0.01 \mathrm{~K}, \xi_{1}(0)=408 \pm 7 \mathrm{~nm}, T_{\mathrm{c} 2}=0.24 \pm 0.01 \mathrm{~K}$, $\xi_{2}(0)=497 \pm 22 \mathrm{~nm}, \frac{T_{c 2}}{T_{c 1}}=0.33 \pm 0.02$, and fit quality is $R=0.9059$; (b) Jones-Hulm-Chandrasekhar (JHC) model. Derived parameters are as follows: $T_{\mathrm{c} 1}=0.77 \pm 0.02 \mathrm{~K}, \xi_{1}(0)=378 \pm 8 \mathrm{~nm}, T_{\mathrm{c} 2}=0.24 \pm 0.02 \mathrm{~K}$, $\xi_{2}(0)=521 \pm 34 \mathrm{~nm}, \frac{T_{c 2}}{T_{c 1}}=0.31 \pm 0.04$, and fit quality is $R=0.9101$; (c) Werthamer-Helfand-Hohenberg model [103,104], for which we use analytical expression given by Baumgartner et al. [105] (B-WHH) model. Derived parameters: $T_{\mathrm{c} 1}=0.74 \pm 0.02 \mathrm{~K}, \xi_{1}(0)=385 \pm 7 \mathrm{~nm}, T_{\mathrm{c} 2}=0.24 \pm 0.01 \mathrm{~K}, \xi_{2}(0)=510 \pm 28 \mathrm{~nm}$, $\frac{T_{c 2}}{T_{c 1}}=0.32 \pm 0.02$, and fit quality is $R=0.9093$. (d) Gor'kov model. Derived parameters: $T_{\mathrm{c} 1}=0.74 \pm 0.02 \mathrm{~K}$, $\xi_{1}(0)=398 \pm 7 \mathrm{~nm}, T_{\mathrm{c} 2}=0.24 \pm 0.01 \mathrm{~K}, \xi_{2}(0)=504 \pm 25 \mathrm{~nm}, \frac{T_{\mathrm{c} 2}}{T_{\mathrm{c} 1}}=0.32 \pm 0.02$, and fit quality is $R=0.9082$. 


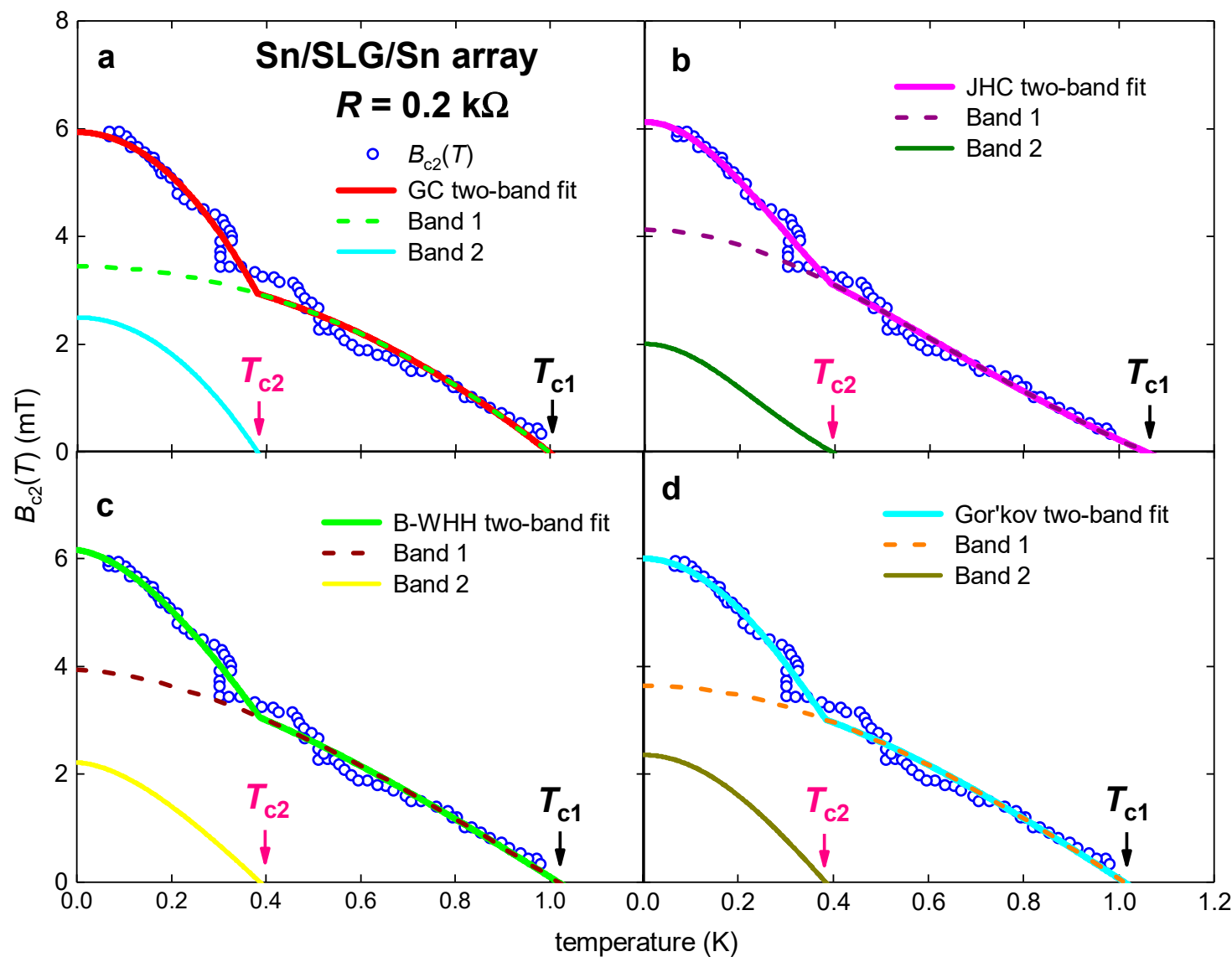

Figure 3. Experimental $B_{\mathrm{c} 2}(T)$ for Sn/SLG/Sn array at gate voltage of $V_{\mathrm{g}}=30 \mathrm{~V}$ [95] and data fits to Equations (5)-(8). $B_{\mathrm{c} 2}$ criterion is $R=0.2 \mathrm{k} \Omega$. (a) GC model. Derived parameters: $T_{\mathrm{c} 1}=1.00 \pm 0.01 \mathrm{~K}$, $\xi_{1}(0)=309 \pm 3 \mathrm{~nm}, T_{\mathrm{c} 2}=0.38 \pm 0.01 \mathrm{~K}, \xi_{2}(0)=363 \pm 7 \mathrm{~nm}, \frac{T_{c 2}}{T_{c 1}}=0.38 \pm 0.01$ and fit quality is $R=0.9847$; (b) JHC model. Derived parameters: $T_{\mathrm{c} 1}=1.06 \pm 0.01 \mathrm{~K}, \xi_{1}(0)=283 \pm 3 \mathrm{~nm}, T_{\mathrm{c} 2}=0.39 \pm 0.01 \mathrm{~K}$, $\xi_{2}(0)=405 \pm 11 \mathrm{~nm}, \frac{T_{c 2}}{T_{c 1}}=0.37 \pm 0.01$, and fit quality is $R=0.9903$; (c) B-WHH model. Derived parameters: $T_{\mathrm{c} 1}=1.02 \pm 0.01 \mathrm{~K}, \xi_{1}(0)=289 \pm 3 \mathrm{~nm}, T_{\mathrm{c} 2}=0.39 \pm 0.01 \mathrm{~K}, \xi_{2}(0)=385 \pm 9 \mathrm{~nm}, \frac{T_{c 2}}{T_{c 1}}=0.38 \pm 0.01$, and fit quality is $R=0.9885$. (d) Gor'kov model. Derived parameters: $T_{\mathrm{c} 1}=1.01 \pm 0.01 \mathrm{~K}, \xi_{1}(0)=300 \pm 3 \mathrm{~nm}$, $T_{\mathrm{c} 2}=0.38 \pm 0.01 \mathrm{~K}, \xi_{2}(0)=374 \pm 7 \mathrm{~nm}, \frac{T_{c 2}}{T_{c 1}}=0.38 \pm 0.01$, and fit quality is $R=0.9873$.

Accordingly, these $B_{\mathrm{c} 2}(T)$ datasets were fitted to four two-band models (Equations (5)-(8)); they are shown in Figures 2 and 3. Deduced parameters, including the ratio of transition temperatures for two bands, $\frac{T_{c 2}}{T_{c 1}}=0.32 \pm 0.02$ for $R=0.01 \mathrm{k} \Omega$ criterion (Figure 2), and $\frac{T_{c 2}}{T_{c 1}}=0.38 \pm 0.01$ for $R=0.2 \mathrm{k} \Omega$ criterion (Figure 3), agreed with each other despite the fact that experimental $B_{\mathrm{c} 2}(T)$ data were processed by four different models.

It should be noted that experimental data of Han et al. [95] show that there is a third upturn in $B_{\mathrm{c} 2}(T)$ that can be seen at lowest experimentally available temperatures of $T<0.1 \mathrm{~K}$ and applied fields of about $B \sim 4.5 \mathrm{mT}$ in Figures 4 and 5 [95], if the criterion of $R \sim 0.05 \mathrm{k} \Omega$ (for the $B_{\mathrm{c} 2}(T)$ definition) are applied.

Despite the fact that authors [61] did not mention the presence of these two upturns in raw experimental $B_{\mathrm{c} 2}(T)$ data and more detailed measurements of $B_{\mathrm{c} 2}(T)$ requires to reveal more accurately the position and parameters for the third band, there is already enough experimental evidence that Sn/SLG/Sn array exhibits at least two-superconducting bands gapping, and thus the report of Han et al. [61] supports the idea that atomically thin films exhibit multiple-band superconducting gapping phenomenon $[85,86]$. 

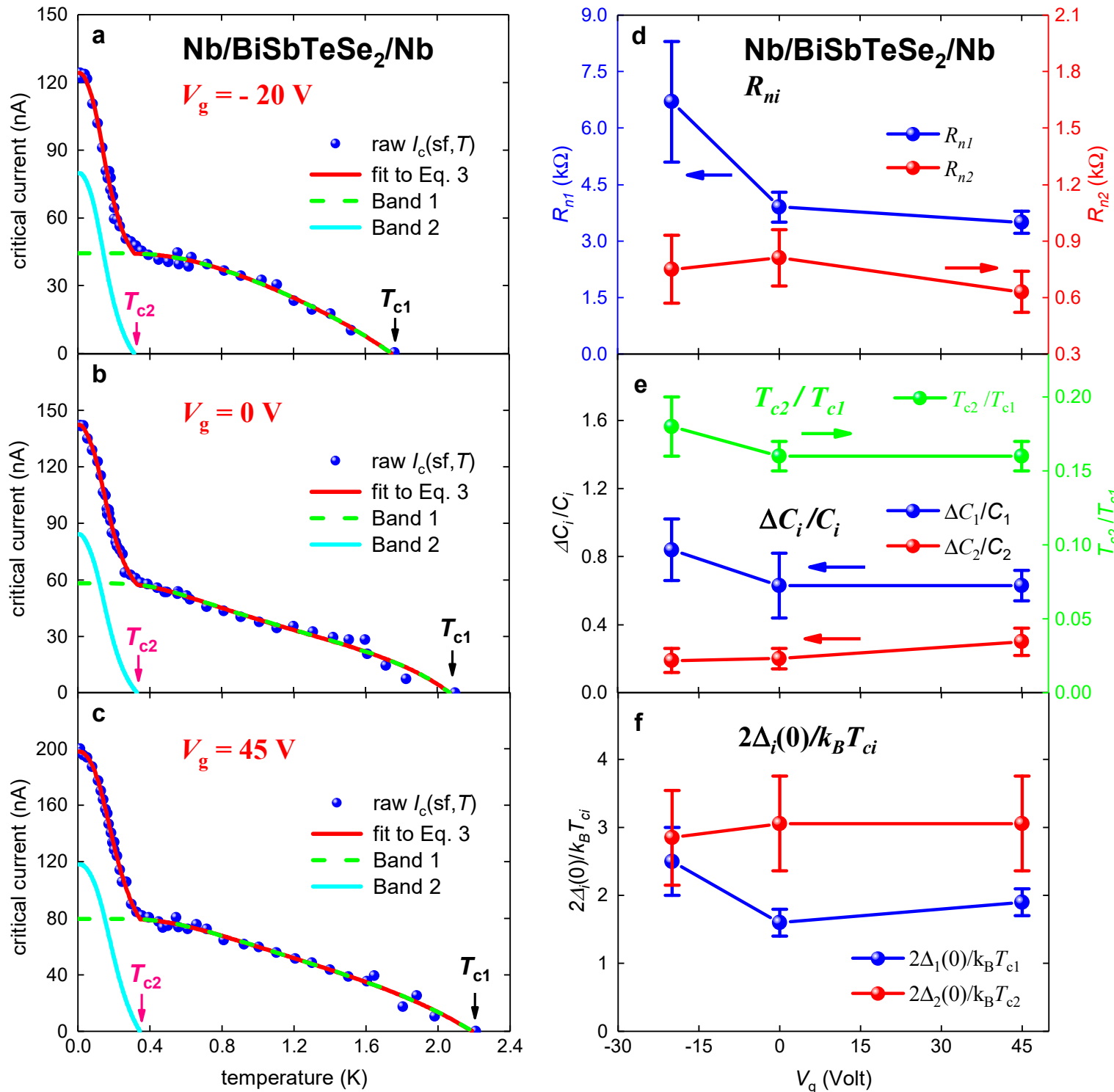

Figure 4. Experimental self-field critical currents $\left(I_{\mathrm{c}}(\mathrm{sf}, T)\right)$ for $\mathrm{Nb} / \mathrm{BiSbTeSe}_{2}$-nanoribbon/ $\mathrm{Nb}$ junction (Sample 1 [82]), data fits to Equation (3), and major deduced parameters. (a) Gate voltage $V_{\mathrm{g}}=-20 \mathrm{~V}$. Derived parameters: $T_{\mathrm{c} 1}=1.74 \pm 0.04 \mathrm{~K}, \Delta_{1}(0)=190 \pm 40 \mu \mathrm{eV}, \Delta C_{1} / C_{1}=0.84 \pm 0.18,2 \Delta_{1}(0) / k_{\mathrm{B}} T_{\mathrm{c} 1}=2.5 \pm 0.5$, $R_{\mathrm{n} 1}=6.7 \pm 1.6 \mathrm{k} \Omega, T_{\mathrm{c} 2}=0.31 \pm 0.02 \mathrm{~K}, \Delta_{2}(0)=38.2 \pm 9.7 \mu \mathrm{eV}, \Delta C_{2} / C_{2}=0.19 \pm 0.07,2 \Delta_{2}(0) / k_{\mathrm{B}} T_{\mathrm{c} 2}=2.85 \pm 0.70$, $R_{\mathrm{n} 2}=0.75 \pm 0.18 \mathrm{k} \Omega, \frac{T_{c 2}}{T_{c 1}}=0.18 \pm 0.02$, and fit quality is $R=0.9953$. (b) Gate voltage $V_{\mathrm{g}}=0 \mathrm{~V}$. Derived parameters: $T_{\mathrm{c} 1}=2.07 \pm 0.03 \mathrm{~K}, \Delta_{1}(0)=144 \pm 11 \mu \mathrm{eV}, \Delta C_{1} / C_{1}=0.63 \pm 0.19,2 \Delta_{1}(0) / k_{\mathrm{B}} T_{\mathrm{c} 1}=1.6 \pm 0.2$, $R_{\mathrm{n} 1}=3.9 \pm 0.4 \mathrm{k} \Omega, T_{\mathrm{c} 2}=0.33 \pm 0.02 \mathrm{~K}, \Delta_{2}(0)=43.5 \pm 8.4 \mu \mathrm{eV}, \Delta C_{2} / C_{2}=0.20 \pm 0.06,2 \Delta_{2}(0) / k_{\mathrm{B}} T_{\mathrm{c} 2}=3.06 \pm 0.70$, $R_{\mathrm{n} 2}=0.81 \pm 0.15 \mathrm{k} \Omega, \frac{T_{c 2}}{T_{c 1}}=0.16 \pm 0.01$, and fit quality is $R=0.9965$. (c) Gate voltage $V_{\mathrm{g}}=45 \mathrm{~V}$. Derived parameters: $T_{\mathrm{c} 1}=2.19 \pm 0.03 \mathrm{~K}, \Delta_{1}(0)=176 \pm 13 \mu \mathrm{eV}, \Delta C_{1} / C_{1}=0.63 \pm 0.09,2 \Delta_{1}(0) / k_{\mathrm{B}} T_{\mathrm{c} 1}=1.9 \pm 0.2$, $R_{\mathrm{n} 1}=3.5 \pm 0.3 \mathrm{k} \Omega, T_{\mathrm{c} 2}=0.34 \pm 0.01 \mathrm{~K}, \Delta_{2}(0)=47.6 \pm 8.7 \mu \mathrm{eV}, \Delta C_{2} / C_{2}=0.30 \pm 0.08,2 \Delta_{2}(0) / k_{\mathrm{B}} T_{\mathrm{c} 2}=3.06 \pm 0.70$, $R_{\mathrm{n} 2}=0.63 \pm 0.11 \mathrm{k} \Omega, \frac{T_{c 2}}{T_{c 1}}=0.16 \pm 0.01$, and fit quality is $R=0.9977$. (d) Derived $R_{\mathrm{ni}}$ as function of gate voltage $V_{\mathrm{g}} ;(\mathbf{e})$ Derived $\frac{T_{c 2}}{T_{c 1}}$ and $\Delta C_{i} / C_{i}$ as function of gate voltage $V_{\mathrm{g}}$. (f) Derived $2 \Delta_{\mathrm{i}}(0) / k_{\mathrm{B}} T_{\mathrm{ci}}$ as function of gate voltage $V_{\mathrm{g}}$. 

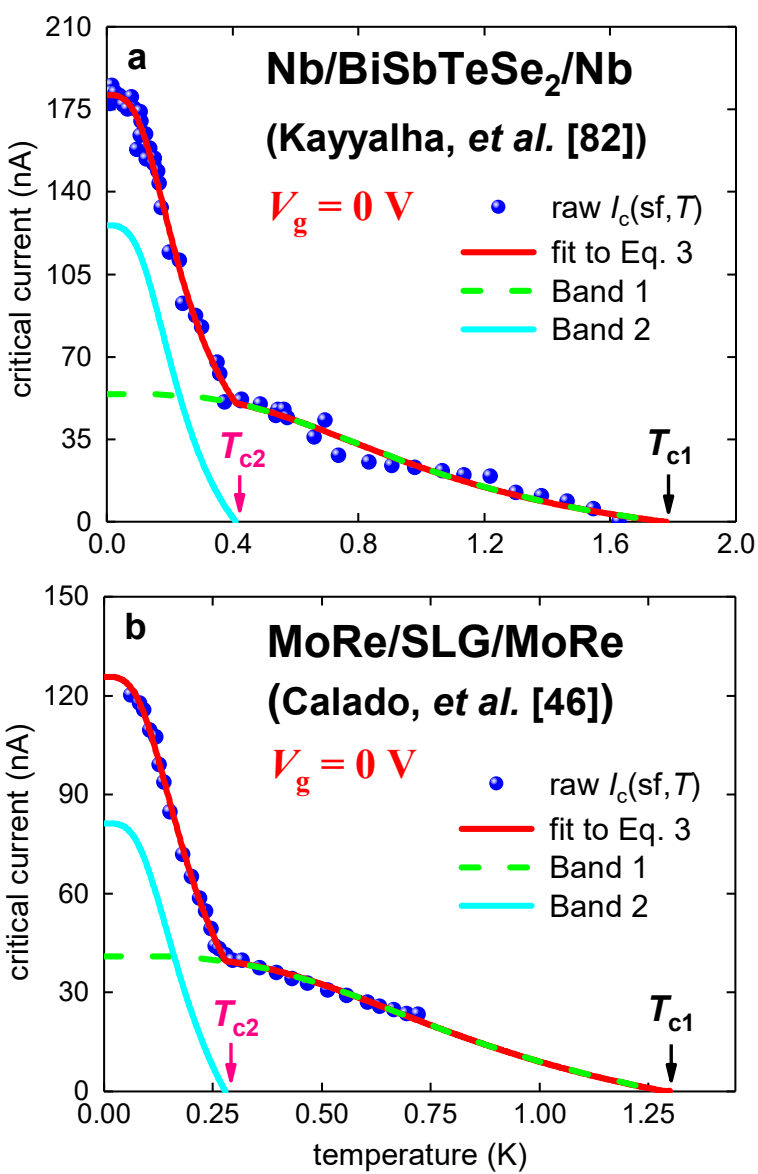

Figure 5. Experimental $I_{\mathrm{c}}(\mathrm{sf}, T)$ for two atomically thin Dirac-cone materials (DCM)-based junctions and fits to Equations (3), (9), (10). (a) Nb/BiSbTeSe $/ \mathrm{Nb}$ (Sample 3 [82]). Derived parameters: $T_{\mathrm{c} 1}=1.8 \pm 0.1 \mathrm{~K}$, $\Delta_{1}(0)=179 \pm 51 \mu \mathrm{eV}, \Delta \mathrm{C} / \mathrm{C}=0.20 \pm 0.04,2 \Delta(0) / k_{\mathrm{B}} T_{\mathrm{c}}=2.3 \pm 0.7, R_{\mathrm{n} 1}=5.2 \pm 1.4 \mathrm{k} \Omega, T_{\mathrm{c} 2}=0.41 \pm 0.02 \mathrm{~K}$, $\Delta_{2}(0)=41 \pm 12 \mu \mathrm{eV}$, and $R_{\mathrm{n} 2}=0.51 \pm 0.15 \mathrm{k} \Omega, \frac{T_{c 2}}{T_{c 1}}=0.23 \pm 0.02, R=0.9954 ;(\mathbf{b})$ MoRe/SLG/MoRe (Sample A [46]). Derived parameters: $T_{\mathrm{c} 1}=1.29 \pm 0.07 \mathrm{~K}, \Delta_{1}(0)=139 \pm 36 \mu \mathrm{eV}, \Delta C / C=0.30 \pm 0.04$, $2 \Delta(0) / k_{\mathrm{B}} T_{\mathrm{c}}=2.5 \pm 0.7, R_{\mathrm{n} 1}=5.3 \pm 1.4 \mathrm{k} \Omega, T_{\mathrm{c} 2}=0.28 \pm 0.01 \mathrm{~K}, \Delta_{2}(0)=30 \pm 8 \mu \mathrm{eV}, R_{\mathrm{n} 2}=0.56 \pm 0.16 \mathrm{k} \Omega$, $\frac{T_{c 2}}{T_{c 1}}=0.22 \pm 0.01$, and $R=0.9981$.

\subsection{Planar $\mathrm{Nb} / \mathrm{BiSbTeSe}_{2}-\mathrm{Nanoribbon/Nb}$ Junctions}

Recently, Kayyalha et al. [82], in their Figure 2 and S1, reported $I_{\mathrm{C}}(\mathrm{sf}, \mathrm{T})$ for five $\mathrm{Nb} / \mathrm{BiSbTeSe}_{2}-$ nanopribbon/ $\mathrm{Nb}$ junctions at different $V_{\mathrm{gs}}$. The thickness of BiSbTeSe ${ }_{2}$ flakes varied from $2 b=30 \mathrm{~nm}$ to $50 \mathrm{~nm}$, and based on reported $\xi(0) \sim 600 \mathrm{~nm}$ [82], the condition of $2 b<\xi(0)[85,86]$ was satisfied for all junctions.

\subsection{1. $\mathrm{Nb} / \mathrm{BiSbTeSe}_{2}-$ Nanoribbon/Nb Junctions}

In Figure 4, we show experimental $I_{\mathrm{c}}(\mathrm{sf}, T)$ datasets for Sample 1 [82] reported for three gate voltages: $V_{\mathrm{g}}=-20 \mathrm{~V}$ (Figure $4 \mathrm{a}$ ), $0 \mathrm{~V}$ (Figure $4 \mathrm{~b}$ ), and $+45 \mathrm{~V}$ (Figure $4 \mathrm{c}$ ). $I_{\mathrm{c}}(\mathrm{sf}, T$ ) fits to Equation (3) were performed for all parameters to be free, as experimental raw datasets were rich enough to carry out these sorts of fits.

Deduced $R_{n i}, \frac{T_{c 1}}{T_{c 2}}, \Delta C_{i} / C_{i}, \Delta_{i}(0)$, and $\frac{2 \Delta_{i}(0)}{k_{B} T_{c, i}}$ for both superconducting bands as functions of $V_{\mathrm{g}}$ are shown in Figure $4 \mathrm{~d}-\mathrm{f}$ ).

It needs to be stressed that within the range of uncertainties, deduced $R_{n 1}$ values are well agree with directly measured values by Kayyalha et al. [82] (these values are reported in Figure 1a of Ref. [82]). Increasingly often, measured raw $I_{\mathrm{c}}(\mathrm{sf}, T)$ data, and especially at high reduced temperatures, are required to reduce the uncertainty for $R_{n 1}$ values. 
Most notable outcome of our analysis is that, within uncertainty ranges, fundamental superconducting parameters for both bands, including the ratio of $\frac{T_{c 2}}{T_{C 1}}$, remain unchanged vs. gate voltage variation in the range from $-20 \mathrm{~V}$ to $45 \mathrm{~V}$. This means that two-band superconducting state in $\mathrm{Nb} / \mathrm{BiSbTeSe}_{2}$-nanoribbon/ $\mathrm{Nb}$ junction is very robust and mostly independent from the change in $V_{\mathrm{g}}$. This is an unexpected result, because there is generally accepted view that because $V_{\mathrm{g}}$ is determined the electronic state in 2D-systems in the normal state, it should also determine the superconducting state. However, performed analysis shows that this is not a case in general. As was already mentioned, there is a need for more frequent measurements of raw $I_{\mathrm{c}}(\mathrm{sf}, T)$ data, which will allow one to reduce uncertainties for all deduced parameters.

\subsection{2. $\mathrm{Nb} / \mathrm{BiSbTeSe}_{2}-\mathrm{Nanoribbon} / \mathrm{Nb}$ Junction}

In Figure 5a, we show experimental $I_{\mathrm{c}}(\mathrm{sf}, \mathrm{T})$ dataset for $\mathrm{Nb} / \mathrm{BiSbTeSe}_{2}$-nanoribbon/ $\mathrm{Nb}$ (Sample 3) reported by Kayyalha et al. [82].

Raw experimental $I_{\mathrm{c}}(\mathrm{sf}, T)$ dataset for this sample was not reach enough at $T \geq 0.6$, and thus we cannot perform the fit to Equation (3) for all parameters to be free. To run the model (Equation (3)), we make the same model restriction, as we did in our previous work [85]:

$$
\begin{gathered}
\frac{\Delta C_{1}}{C_{1}}=\frac{\Delta C_{2}}{C_{2}}=\frac{\Delta C}{C}, \\
\frac{2 \Delta_{1}(0)}{k_{B} T_{1}}=\frac{2 \Delta_{2}(0)}{k_{B} T_{2}}=\frac{2 \Delta(0)}{k_{B} T_{c}},
\end{gathered}
$$

i.e., we forced $\Delta C_{i} / C_{i}$ and $\frac{2 \Delta_{i}(0)}{k_{B} T_{c, i}}$ values to be the same for both bands. As a result, deduced $R_{n i}, T_{c i}$, $\frac{T_{c 2}}{T_{c 1}} \sim \frac{1}{4}, \Delta C / C, \Delta_{i}(0)$ and $\frac{2 \Delta(0)}{k_{B} T_{c}}$ for this junction are very close to ones deduced for Sample 1 (Figure 4 ).

\subsection{Planar MoRe/SLG/MoRe Junction}

To demonstrate that findings in regard of $\mathrm{Nb} / \mathrm{BiSbTeSe}_{2}$-nanoribbon/ $\mathrm{Nb}$ junctions are generic for a much wide range of atomically-thin DCM-based Josephson junctions, in Figure $5 \mathrm{~b}$ we show raw $I_{\mathrm{c}}(\mathrm{sf}, T)$ dataset and fit to the model (Equation (3)) for MoRe/SLG/MoRe reported by Calado et al. [46] for their Device A [46]. For the $I_{\mathrm{c}}(\mathrm{sf}, T)$ fit for this device, we used the same parameters restrictions (Equations (9) and (10)), as for $\mathrm{Nb} / \mathrm{BiSbTeSe}_{2}$-nanoribbon/ $\mathrm{Nb}$ Sample 3 [82].

In work [85], this $I_{\mathrm{c}}(\mathrm{sf}, T)$ dataset for MoRe/SLG/MoRe Device A [46] was already analyzed. What was found in this paper was that there is remarkable and practically undistinguishable similarity between reduced $I_{\mathrm{c}}(\mathrm{sf}, T)$ datasets and fits for $\mathrm{Nb} / \mathrm{BiSbTeSe}_{2}$-nanoribbon/ $\mathrm{Nb}[48]$ and MoRe/SLG/MoRe [46] junctions (Figure 5). In an attempt to further extend atomically-thin S/DCM/S junctions, in next Section we analyze $I_{\mathrm{c}}(\mathrm{sf}, \mathrm{T})$ data for $\mathrm{Nb} /\left(\mathrm{Bi}_{0.06} \mathrm{Sb}_{0.94}\right)_{2} \mathrm{Te}_{3}$-nanoribbon/ $\mathrm{Nb}$ junction [94].

\subsection{Planar $\mathrm{Nb} /\left(\mathrm{Bi}_{0.06} \mathrm{Sb}_{0.94}\right)_{2} \mathrm{Te}_{3}-\mathrm{Nanoribbon} / \mathrm{Nb}$ Junction}

In Figure $6, I_{\mathrm{c}}(\mathrm{sf}, \mathrm{T})$ in $\mathrm{Nb} /\left(\mathrm{Bi}_{0.06} \mathrm{Sb}_{0.94}\right)_{2} \mathrm{Te}_{3}$-nanoribbon/ $\mathrm{Nb}$ reported by Schüffelgen et al. [94] are shown. TI nanoribbon has thickness of $2 b=10 \mathrm{~nm}$, and, thus the condition of $2 b<\xi(0)[85,86]$ is satisfied.

Due to the fact that the reported $I_{\mathrm{c}}(\mathrm{sf}, T)$ dataset was not rich enough at high reduced temperatures, we restricted the model by utilizing Equations (9) and (10). Overall, fitted curves and all deduced parameters were very close to one reported by Borzenets et al. [49] for MoRe/SLG/MoRe junctions (which we processed and showed in our previous paper [85] in Figure 7). 


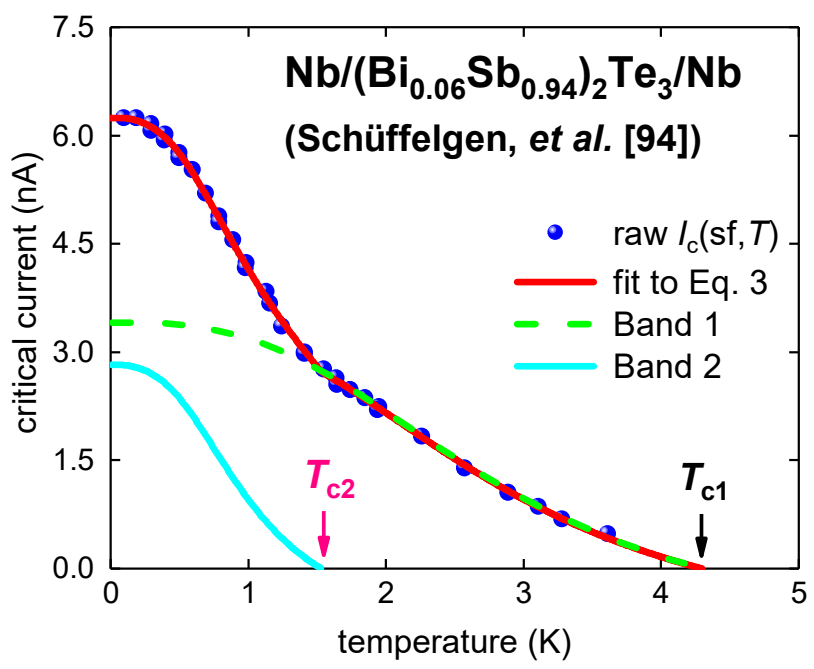

Figure 6. Experimental $I_{\mathrm{c}}(\mathrm{sf}, T)$ for atomically thin DCM-based junction $\mathrm{Nb} /\left(\mathrm{Bi}_{0.06} \mathrm{Sb}_{0.94}\right)_{2} \mathrm{Te}_{3}-$ nanoribbon/ $\mathrm{Nb}$ [94] and fit to Equations (3), (9) and (10). Derived parameters: $T_{\mathrm{c} 1}=4.30 \pm 0.07 \mathrm{~K}$, $\Delta_{1}(0)=530 \pm 7 \mu \mathrm{eV}, \Delta C / C=0.28 \pm 0.04,2 \Delta(0) / k_{\mathrm{B}} T_{\mathrm{c}}=2.87 \pm 0.05, R_{\mathrm{n} 1}=244 \pm 32 \Omega, T_{\mathrm{c} 2}=1.53 \pm 0.03 \mathrm{~K}$, $\Delta_{2}(0)=189 \pm 3 \mu \mathrm{eV}, R_{\mathrm{n} 2}=105 \pm 16 \Omega, \frac{T_{c 2}}{T_{c 1}}=0.36 \pm 0.01$ and $R=0.9995$.

\section{Discussion}

It should be noted that the idea of multiple-band superconductivity in bulk superconductors was proposed by Suhl et al. [107] in 1959, and it took more than forty years to discover the first two-band BCS superconductor $\left(\mathrm{MgB}_{2}\right)$ [108] and about fifty years to discover multiple-band iron-based superconductors in 2006 [109]. Interband scattering in these materials have been discussed in details elsewhere [24,110-112].

It needs to be mentioned that Shalnikov discussed the discovery of the $T_{\mathrm{c}}$ increase in thin films [113], who reported the effect for lead and tin thin films more than eighty years ago. Three-fold increase in the transition temperature of thin granular $\mathrm{Al}$ films was reported three decades later by Cohen and Abeles [114], and the superconductivity in granular Al films is still active scientific topic $[115,116]$; the discussion of this effect in intrinsic superconductors, however, is beyond the scope of this paper.

It needs to be stressed that Calado et al. [46] in 2015 emphasized the necessity for a new model to explain the upturn in $I_{\mathrm{c}}(\mathrm{sf}, T)$ registered in their MoRe/SLG/MoRe junction (Device A) at $T \sim \frac{1}{4} T_{\mathcal{c}}$ (which we show in Figure $5 \mathrm{~b}$ ), because this $I_{\mathrm{c}}(\mathrm{sf}, T)$ enhancement was not possible to explain using either the Eilenberger model (which is used to describe clean S/N/S junctions) [117] or the Usadel model (which describes diffusive $\mathrm{S} / \mathrm{N} / \mathrm{S}$ junctions) [118].

Our explanation for this upturn [85], which is well aligned with the $I_{\mathrm{c}}(\mathrm{sf}, T)$ upturn in natural atomically thin superconductors [86], is that this $I_{\mathrm{C}}(\mathrm{sf}, T)$ enhancement is due to a new superconducting band opening phenomenon when sample dimensions become smaller than some critical value. For this critical value, we proposed to use [86] the out-of-plane coherence length, $\xi_{c}(0)$, which is still, after expanding our analysis herein, a good choice for the criterion.

It should be pointed out that this new opening band phenomenon does not necessarily cause the increase in observed transition temperature in comparison with "bulk" material. For instance, in pure $\mathrm{Nb}$ films [119], this new "thin film" band has lower transition temperature in comparison with "bulk" band [86]. In these circumstances, the researchers are not able to explore the further creation of devices or films for new superconducting band.

Thus, in many atomically thin films, which in fact exhibit a new band opening phenomenon, this effect has not been registered yet, because there is no guarantee that something important/interesting can be observed at low reduced temperatures, well below "bulk" or observed $T_{\mathrm{c}}$ for given atomically thin film. 
It should be noted that the effect of new superconducting band opening [86] in atomically thin films can be detected using any experimental techniques that are sensitive to additional band(s) crossing the Fermi surface. To date, most evident confirmations for the phenomenon are related to the $I_{\mathrm{C}}(\mathrm{sf}, T)$ upturn $[43,85,86]$ and $B_{\mathrm{c} 2}(T)$ upturn [43]; however, other techniques also should be able to detect this.

In this regard, the observation of the $I_{\mathrm{C}}(\mathrm{sf}, T)$ upturn reported by Li et al. [78] in their Figure 4a at $T=2.5 \mathrm{~K}$ in Nb/Cd${ }_{3} \mathrm{As}_{2}$-nanowire/ $\mathrm{Nb}$ junction should be mentioned. However, raw experimental $I_{\mathrm{c}}(\mathrm{sf}, T)$ dataset [78] was limited by measurements at $T<3.5 \mathrm{~K}$, and thus we are not able to perform the analysis for this very interesting atomically-narrow $\mathrm{S} / \mathrm{TI} / \mathrm{S}$ junction at the moment.

There are very interesting results reported by Sasaki et al. [120] and by Andersen et al. [121], who found that temperature-dependent $B_{\mathrm{c} 2}(T)$, in nanostructures of topological insulators, cannot be explained by single-band WHH model $[103,104]$. However, reported, to date, raw experimental $B_{\mathrm{c} 2}(T)$ datasets $[119,120]$ are insufficient to perform two-band model fit to reveal the presence of additional band at low reduced temperatures in these structures.

We also need to mention an interesting research field of interfaced superconductivity [71,122-125], where, as was proposed earlier, the enhancement of the superconductivity is also due to new superconducting band opening [86]. However, the discussion of this interesting field is beyond the scope of this paper.

\section{Conclusions}

In this paper, an analysis of recently reported experimental data on induced superconducting state in atomically thin Dirac-cone films was performed. It was shown that the phenomenon of the new superconducting band opening in atomically thin films $[85,86]$, when the film thickness becomes thinner than the ground state out-of-plane coherence length, $\xi_{\mathrm{c}}(0)$, can be extended to an induced superconducting state in atomically thin DCM, as one was established before for natural superconductors, i.e., pure $\mathrm{Nb}$, exfoliated $2 \mathrm{H}-\mathrm{TaS}_{2}$, double-atomic layer $\mathrm{FeSe}$, and a few layers of stanene [9].

Funding: This research was funded by the State Assignment of Minobrnauki of Russia, theme "Pressure" No. AAAA-A18-118020190104-3, and by Act 211 Government of the Russian Federation, contract No. 02.A03.21.0006.

Acknowledgments: Author would like to thank Srijit Goswami and Lieven Vandersypen (Kavli Institute of Nanoscience, Delft University of Technology, The Netherlands) for providing raw self-field critical current data for the MoRe/SLG/MoRe devices analyzed in this work.

Conflicts of Interest: The funders had no role in the design of the study; in the collection, analyses, or interpretation of data; in the writing of the manuscript; or in the decision to publish the results.

\section{References}

1. Hirsch, J.E.; Maple, M.B.; Marsiglio, F. Superconducting materials classes: Introduction and overview. Physica C 2015, 514, 1-8. [CrossRef]

2. Uemura, Y.J.; Luke, G.M.; Sternlieb, B.J.; Brewer, J.H.; Carolan, J.F.; Hardy, W.N.; Kadono, R.; Kempton, J.R.; Kiefl, R.F.; Kreitzman, S.R. Universal correlations between $T_{\mathrm{c}}$ and $\frac{n_{s}}{m^{*}}$ (carrier density over effective mass) in high- $T_{\mathrm{c}}$ cuprate. Phys. Rev. Lett. 1989, 62, 2317-2320. [CrossRef] [PubMed]

3. Uemura, Y.J. Condensation, excitation, pairing, and superfluid density in high- $T_{\mathrm{C}}$ superconductors: The magnetic resonance mode as a roton analogue and a possible spin-mediated pairing. J. Phys. Condens. Matter 2004, 16, S4515-S4540. [CrossRef]

4. Drozdov, A.P.; Eremets, M.I.; Troyan, I.A.; Ksenofontov, V.; Shylin, S.I. Conventional superconductivity at 203 kelvin at high pressures in the sulfur hydride system. Nature 2015, 525, 73-76. [CrossRef] [PubMed]

5. Somayazulu, M.; Ahart, M.; Mishra, A.K.; Geballe, Z.M.; Baldini, M.; Meng, Y.; Struzhkin, V.V.; Hemley, R.J. Evidence for superconductivity above $260 \mathrm{~K}$ in lanthanum superhydride at megabar pressures. Phys. Rev. Lett. 2019, 122, 027001. [CrossRef] [PubMed] 
6. Mozaffari, S.; Sun, D.; Minkov, V.S.; Drozdov, A.P.; Knyazev, D.; Betts, J.B.; Einaga, M.; Shimizu, K.; Eremets, M.I.; Balicas, L. Superconducting phase-diagram of $\mathrm{H}_{3} \mathrm{~S}$ under high magnetic fields. Nat. Commun. 2019, 10, 2522. [CrossRef] [PubMed]

7. Drozdov, A.P.; Kong, P.P.; Minkov, V.S.; Besedin, S.P.; Kuzovnikov, M.A.; Mozaffari, S.; Balicas, L.; Balakirev, F.F.; Graf, D.E.; Prakapenka, V.B. Superconductivity at $250 \mathrm{~K}$ in lanthanum hydride under high pressures. Nature 2019, 569, 528-531. [CrossRef] [PubMed]

8. Talantsev, E.F. Classifying superconductivity in compressed $\mathrm{H}_{3}$ S. Mod. Phys. Lett. B 2019, 33, 1950195. [CrossRef]

9. Talantsev, E.F. Classifying hydrogen-rich superconductors. Mater. Res. Express 2019, 6, 106002. [CrossRef]

10. Hardy, W.N.; Bonn, D.A.; Morgan, D.C.; Liang, R.; Zhang, K. Precision measurements of the temperature dependence of 1 in $\mathrm{YBa}_{2} \mathrm{Cu}_{3} \mathrm{O}_{6.95}$ : Strong evidence for nodes in the gap function. Phys. Rev. Lett. 1993, 70, 3999-4002. [CrossRef]

11. Bednorz, J.G.; Mueller, K.A. Possible high Tc superconductivity in the Ba-La-Cu-O system. Z. Phys. B 1986, 64, 189-193. [CrossRef]

12. Won, H.; Maki, K. $d$-wave superconductor as a model of high- $T_{\mathrm{c}}$ superconductors. Phys. Rev. B 1994, 49, 1397-1402. [CrossRef] [PubMed]

13. Hirsch, J.E. Hole superconductivity. Phys. Lett. A 1989, 134, 451-455. [CrossRef]

14. Bianconi, A. On the possibility of new high $T_{\mathrm{c}}$ superconductors by producing metal heterostructures as in cuprate perovskites. Solid State Commun. 1994, 89, 933-936. [CrossRef]

15. Bouquet, F.; Wang, Y.; Fisher, R.A.; Hinks, D.G.; Jorgensen, J.D.; Junod, A.; Phillips, N.E. Phenomenological two-gap model for the specific heat of $\mathrm{MgB}_{2}$. Europhys. Lett. 2001, 56, 856-862. [CrossRef]

16. Bauer, E.; Paul, C.H.; Berger, S.T.; Majumdar, S.; Michor, H.; Giovannini, M.; Saccone, A.; Bianconi, A. Thermal conductivity of superconducting $\mathrm{MgB}_{2}$. J. Phys. Condens. Matter 2001, 13, L487-L494. [CrossRef]

17. Carrington, A.; Manzano, F. Magnetic penetration depth of $\mathrm{MgB}_{2}$. Physica C 2003, 385, 205-214. [CrossRef]

18. Agrestini, S.; Metallo, C.; Filippi, M.; Simonelli, L.; Campi, G.; Sanipoli, C.; Liarokapis, E.; De Negri, S.; Giovannini, M.; Saccone, A. Substitution of Sc for $\mathrm{Mg}$ in $\mathrm{MgB}_{2}$ : Effects on transition temperature and Kohn anomaly. Phys. Rev. B 2004, 70, 134514. [CrossRef]

19. Mazin, I.I.; Singh, D.J.; Johannes, M.D.; Du, M.H. Unconventional superconductivity with a sign reversal in the order parameter of $\mathrm{LaFeAsO}_{1-\mathrm{x}} \mathrm{F}_{\mathrm{x}}$. Phys. Rev. Lett. 2008, 101, 057003. [CrossRef]

20. Kuroki, K.; Onari, S.; Arita, R.; Usui, H.; Tanaka, Y.; Kontani, H.; Aoki, H. Unconventional pairing originating from the disconnected Fermi surfaces of superconducting $\mathrm{LaFeAsO}_{1-\mathrm{x}} \mathrm{F}_{\mathrm{x}}$. Phys. Rev. Lett. 2008, 101, 087004. [CrossRef] [PubMed]

21. Innocenti, D.; Caprara, S.; Poccia, N.; Ricci, A.; Valletta, A.; Bianconi, A. Shape resonance for the anisotropic superconducting gaps near a Lifshitz transition: The effect of electron hopping between layers. Supercond. Sci. Technol. 2011, 24, 015012. [CrossRef]

22. Bianconi, A.; Innocenti, D.; Valletta, A.; Perali, A. Shape resonances in superconducting gaps in a 2DEG at oxide-oxide interface. J. Phys. Conf. Ser. 2014, 529, 012007. [CrossRef]

23. Hosono, H.; Tanabe, K.; Takayama-Muromachi, E.; Kageyama, H.; Yamanaka, S.; Kumakura, H.; Nohara, M.; Hiramatsu, H.; Fujitsu, S. Exploration of new superconductors and functional materials, and fabrication of superconducting tapes and wires of iron pnictides. Sci. Technol. Adv. Mater. 2015, 16, 033503. [CrossRef] [PubMed]

24. Hosono, H.; Kuroki, K. Iron-based superconductors: Current status of materials and pairing mechanism. Physica C 2015, 514, 399-422. [CrossRef]

25. Bianconi, A.; Jarlborg, T. Superconductivity above the lowest Earth temperature in pressurized sulfur hydride. EPL (Europhys. Lett.) 2015, 112, 37001. [CrossRef]

26. Hirsch, J.E.; Marsiglio, F. Hole superconductivity in $\mathrm{H}_{2} \mathrm{~S}$ and other sulfides under high pressure. Physica $\mathrm{C}$ 2015, 511, 45-49. [CrossRef]

27. Souza, T.X.R.; Marsiglio, F. Systematic study of the superconducting critical temperature in two- and three-dimensional tight-binding models: A possible scenario for superconducting $\mathrm{H}_{3} \mathrm{~S}$. Phys. Rev. B 2016, 94, 184509. [CrossRef]

28. Harshman, D.R.; Fiory, A.T. Compressed $\mathrm{H}_{3}$ S: Inter-sublattice Coulomb coupling in a high- $T_{\mathrm{C}}$ superconductor. J. Phys. Condens. Matter 2017, 29, 445702. [CrossRef] 
29. Bang, Y.; Stewart, G.R. Superconducting properties of the s \pm -wave state: Fe-based superconductors. J. Phys. Condens. Matter 2017, 29, 123003. [CrossRef]

30. Kaplan, D.; Imry, Y. High-temperature superconductivity using a model of hydrogen bonds. Proc. Natl. Acad. Sci. USA 2018, 115, 5709-5713. [CrossRef]

31. Moskvin, A.S.; Panov, Y.D. Topological structures in unconventional scenario for 2D cuprates. J. Supercond. Nov. Magn. 2019, 32, 61-84. [CrossRef]

32. Ye, J.T.; Zhang, Y.J.; Akashi, R.; Bahramy, M.S.; Arita, R.; Iwasa, Y. Superconducting dome in a gate-tuned band insulator. Science 2012, 338, 1193-1196. [CrossRef] [PubMed]

33. Qian, T.; Wang, X.-P.; Jin, W.-C.; Zhang, P.; Richard, P.; Xu, G.; Dai, X.; Fang, Z.; Guo, J.-G.; Chen, X.-L. Absence of a holelike Fermi surface for the iron-based $\mathrm{K}_{0.8} \mathrm{Fe}_{1.7} \mathrm{Se}_{2}$ superconductor revealed by angle-resolved photoemission spectroscopy. Phys. Rev. Lett. 2011, 106, 187001. [CrossRef] [PubMed]

34. Hashimoto, K.; Cho, K.; Shibauchi, T.; Kasahara, S.; Mizukami, Y.; Katsumata, R.; Tsuruhara, Y.; Terashima, T.; Ikeda, H.; Tanatar, M.A. A sharp peak of the zero-temperature penetration depth at optimal composition in $\mathrm{BaFe}_{2}\left(\mathrm{As}_{1-\mathrm{x}} \mathrm{P}_{\mathrm{x}}\right)_{2}$. Science 2012, 336, 1554-1557. [CrossRef] [PubMed]

35. Shang, T.; Philippe, J.; Verezhak, J.A.T.; Guguchia, Z.; Zhao, J.Z.; Chang, L.-J.; Lee, M.K.; Gawryluk, D.J.; Pomjakushina, E.; Shi, M. Nodeless superconductivity and preserved time-reversal symmetry in the noncentrosymmetric $\mathrm{Mo}_{3} \mathrm{P}$ superconductor. Phys. Rev. B 2019, 99, 184513. [CrossRef]

36. Holm, R.; Meissner, W. Messungen mit Hilfe von flüssigem Helium. XIII. Kontaktwiderstand zwischen Supraleitern und Nichtsupraleitern (Measurements using liquid helium. XIII. Contact resistance between superconductors and non-superconductors). Z. Phys. 1932, 74, 715-735. [CrossRef]

37. Natterer, F.D.; Ha, J.; Baek, H.; Zhang, D.; Cullen, W.G.; Zhitenev, N.B.; Kuk, Y.; Stroscio, J.A. Scanning tunneling spectroscopy of proximity superconductivity in epitaxial multilayer graphene. Phys. Rev. B 2016, 93, 045406. [CrossRef]

38. Kim, H.; Miyata, Y.; Hasegawa, Y. Superconducting proximity effect on a Rashba-split Pb/Ge $(111)-\sqrt{ } 3 \times \sqrt{ } 3$ surface. Supercond. Sci. Technol. 2016, 29, 084006. [CrossRef]

39. Ambegaokar, V.; Baratoff, A. Tunneling between superconductors. Phys. Rev. Lett. 1963, 10, 486-489. [CrossRef]

40. Ambegaokar, V.; Baratoff, A. Errata: Tunneling between superconductors. Phys. Rev. Lett. 1963, 11, 104. [CrossRef]

41. Novoselov, K.S.; Geim, A.K.; Morozov, S.V.; Jiang, D.; Zhang, Y.; Dubonos, S.V.; Grigorieva, I.V.; Firsov, A.A. Electric field effect in atomically thin carbon films. Science 2004, 306, 666-669. [CrossRef] [PubMed]

42. Lee, G.H.; Kim, S.; Jhi, S.-H.; Lee, H.-J. Ultimately short ballistic vertical graphene Josephson junctions. Nat. Commun. 2015, 6, 6181. [CrossRef] [PubMed]

43. Liao, M.; Zang, Y.; Guan, Z.; Li, H.; Gong, Y.; Zhu, K.; Hu, X.-P.; Zhang, D.; Xu, Y.; Wang, Y.-Y. Superconductivity in few-layer stanene. Nat. Phys. 2018, 14, 344-348. [CrossRef]

44. Heersche, H.B.; Jarillo-Herrero, P.; Oostinga, J.B.; Vandersypen, L.M.K.; Morpurgo, A.F. Bipolar supercurrent in graphene. Nature 2007, 446, 56-59. [CrossRef] [PubMed]

45. Du, X.; Skachko, I.; Andrei, E.Y. Josephson current and multiple Andreev reflections in graphene SNS junctions. Phys. Rev. B 2008, 77, 184507. [CrossRef]

46. Calado, V.E.; Goswami, S.; Nanda, G.; Diez, M.; Akhmerov, A.R.; Watanabe, K.; Taniguchi, T.; Klapwijk, T.M.; Vandersypen, L.M.K. Ballistic Josephson junctions in edge-contacted graphene. Nat. Nanotechnol. 2015, 10, 761-764. [CrossRef] [PubMed]

47. Ben Shalom, M.; Zhu, M.J.; Fal'ko, V.I.; Mishchenko, A.; Kretinin, A.V.; Novoselov, K.S.; Woods, C.R.; Watanabe, K.; Taniguchi, T.; Geim, A.K. Quantum oscillations of the critical current and high-field superconducting proximity in ballistic graphene. Nat. Phys. 2016, 12, 318-322. [CrossRef]

48. Amet, F.; Ke, C.T.; Borzenets, I.V.; Wang, J.; Watanabe, K.; Taniguchi, T.; Deacon, R.S.; Yamamoto, M.; Bomze, Y.; Tarucha, S. Supercurrent in the quantum Hall regime. Science 2016, 352, 966-969. [CrossRef] [PubMed]

49. Borzenets, I.V.; Amet, F.; Ke, C.T.; Draelos, A.W.; Wei, M.T.; Seredinski, A.; Watanabe, K.; Taniguchi, T.; Bomze, Y.; Yamamoto, M. Ballistic graphene Josephson junctions from the short to the long junction regimes. Phys. Rev. Lett. 2016, 117, 237002. [CrossRef] [PubMed]

50. Island, J.O.; Steele, G.A.; van der Zant, H.S.J.; Castellanos-Gomez, A. Thickness dependent interlayer transport in vertical $\mathrm{MoS}_{2}$ Josephson. 2D Mater. 2016, 3, 031002. [CrossRef] 
51. Zhu, M.J.; Kretinin, A.V.; Thompson, M.D.; Bandurin, D.A.; Hu, S.; Yu, G.L.; Birkbeck, J.; Mishchenko, A.; Vera-Marun, I.J.; Watanabe, K. Edge currents shunt the insulating bulk in gapped graphene. Nat. Commun. 2017, 8, 14552. [CrossRef] [PubMed]

52. Veldhorst, M.; Snelder, M.; Hoek, M.; Gang, T.; Guduru, V.K.; Wang, X.L.; Zeitler, U.; Van Der Wiel, W.G.; Golubov, A.A.; Hilgenkamp, H. Josephson supercurrent through a topological insulator surface state. Nat. Mater. 2012, 11, 417-421. [CrossRef] [PubMed]

53. Kurter, C.; Finck, A.D.K.; Hor, Y.S.; Van Harlingen, D.J. Evidence for an anomalous current-phase relation in topological insulator Josephson junctions. Nat. Commun. 2015, 6, 7130. [CrossRef] [PubMed]

54. Nanda, G.; Aguilera-Servin, J.L.; Rakyta, P.; Kormányos, A.; Kleiner, R.; Koelle, D.; Watanabe, K.; Taniguchi, T.; Vandersypen, L.M.K.; Goswami, S. Current-phase relation of ballistic graphene Josephson junctions. Nano Lett. 2017, 17, 3396-3401. [CrossRef] [PubMed]

55. Yankowitz, M.; Chen, S.; Polshyn, H.; Watanabe, K.; Taniguchi, T.; Graf, D.; Young, A.F.; Dean, C.R. Tuning superconductivity in twisted bilayer graphene. Science 2019, 363, 1059-1064. [CrossRef] [PubMed]

56. Lucignano, P.; Alfè, D.; Cataudella, V.; Ninno, D.; Cantele, G. The crucial role of atomic corrugation on the flat bands and energy gaps of twisted bilayer graphene at the "magic angle" $\theta \sim 1.08^{\circ}$. Phys. Rev. B 2019, 99, 195419. [CrossRef]

57. Giubileo, F.; Romeo, F.; Di Bartolomeo, A.; Mizuguchi, Y.; Romano, P. Probing unconventional pairing in $\mathrm{LaO}_{0.5} \mathrm{~F}_{0.5} \mathrm{BiS}_{2}$ layered superconductor by point contact spectroscopy. J. Phys. Chem. Solids 2018, 118, 192-199. [CrossRef]

58. Kizilaslan, O.; Truccato, M.; Simsek, Y.; Aksan, M.A.; Koval, Y.; Müller, P. Interlayer tunneling spectroscopy of mixed-phase BSCCO superconducting whiskers. Supercond. Sci. Technol. 2016, 29, 065013. [CrossRef]

59. Fête, A.; Rossi, L.; Augieri, A.; Senatore, C. Ionic liquid gating of ultra-thin YBa2Cu3O7-x films. Appl. Phys. Lett. 2016, 109, 192601. [CrossRef]

60. Mueller, P.; Koval, Y.; Lazareva, Y.; Steiner, C.; Wurmehl, S.; Buechner, B.; Stuerzer, T.; Johrendt, D. C-axis transport of pnictide superconductors. Phys. Status Solidi B 2017, 254, 1600157. [CrossRef]

61. Fête, A.; Senatore, C. Strong improvement of the transport characteristics of $\mathrm{YBa}_{2} \mathrm{Cu}_{3} \mathrm{O}_{7-\mathrm{x}}$ grain boundaries using ionic liquid gating. Sci. Rep. 2017, 8, 17703. [CrossRef] [PubMed]

62. Paradiso, N.; Nguyen, A.-T.; Kloss, K.E.; Strunk, C. Phase slip lines in superconducting few-layer $\mathrm{NbSe}_{2}$ crystals. 2D Mater. 2019, 6, 025039. [CrossRef]

63. Wu, Y.; Xiao, H.; Li, Q.; Li, X.; Li, Z.; Mu, G.; Jiang, D.; Hu, T.; Xie, X.M. The transport properties in graphene/single-unit-cell cuprates van der Waals heterostructure. Supercond. Sci. Technol. 2019, 32, 085007. [CrossRef]

64. Guo, J.G.; Chen, X.; Jia, X.Y.; Zhang, Q.H.; Liu, N.; Lei, H.C.; Li, S.Y.; Gu, L.; Jin, S.F.; Chen, X.L. Quasi-two-dimensional superconductivity from dimerization of atomically ordered $\mathrm{AuTe}_{2} \mathrm{Se}_{4 / 3}$ cubes. Nat. Commun. 2017, 8, 871. [CrossRef] [PubMed]

65. Pan, J.; Guo, C.; Song, C.; Lai, X.; Li, H.; Zhao, W.; Zhang, H.; Mu, G.; Bu, K.; Lin, T. Enhanced superconductivity in restacked $\mathrm{TaS}_{2}$ nanosheets. J. Am. Chem. Soc. 2017, 139, 4623-4626. [CrossRef] [PubMed]

66. Ma, Y.; Pan, J.; Guo, C.; Zhang, X.; Wang, L.; Hu, T.; Mu, G.; Huang, F.; Xie, X. Unusual evolution of $B_{\mathrm{c} 2}$ and $T_{\mathrm{c}}$ with inclined fields in restacked $\mathrm{TaS}_{2}$ nanosheets. NPJ Quantum Mater. 2018, 3, 34. [CrossRef]

67. Desrat, W.; Moret, M.; Briot, O.; Ngo, T.-H.; Piot, B.A.; Jabakhanji, B.; Gil, B. Superconducting Ga/GaSe layers grown by van der Waals epitaxy. Mater. Res. Express 2018, 5, 045901. [CrossRef]

68. Liu, C.; Lian, C.-S.; Liao, M.-H.; Wang, Y.; Zhong, Y.; Ding, C.; Li, W.; Song, C.-L.; He, K.; Ma, X.-C. Two-dimensional superconductivity and topological states in $\mathrm{PdTe}_{2}$ thin films. Phys. Rev. Mater. 2018, 2, 094001. [CrossRef]

69. Peng, J.; Yu, Z.; Wu, J.; Zhou, Y.; Guo, Y.; Li, Z.; Zhao, J.; Wu, C.; Xie, Y. Disorder enhanced superconductivity toward $\mathrm{TaS}_{2}$ monolayer. ACS Nano 2018, 12, 9461-9466. [CrossRef]

70. De La Barrera, S.C.; Sinko, M.R.; Gopalan, D.P.; Sivadas, N.; Seyler, K.L.; Watanabe, K.; Taniguchi, T.; Tsen, A.W.; $\mathrm{Xu}, \mathrm{X}$; Xiao, D. Tuning Ising superconductivity with layer and spin-orbit coupling in two-dimensional transition-metal dichalcogenides. Nat. Commun. 2018, 9, 1427. [CrossRef]

71. Di Castro, D.; Balestrino, G. Superconductivity in interacting interfaces of cuprate-based heterostructures. Supercond. Sci. Technol. 2018, 31, 073001. [CrossRef]

72. Wu, Y.; He, J.; Liu, J.; Xing, H.; Mao, Z.; Liu, Y. Dimensional reduction and ionic gating induced enhancement of superconductivity in atomically thin crystals of $2 \mathrm{H}-\mathrm{TaSe}_{2}$. Nanotechnology 2019, 30, 035702. [CrossRef] 
73. Talantsev, E.F. Angular dependence of the upper critical field in randomly restacked 2D superconducting nanosheets. Supercond. Sci. Technol. 2019, 32, 015013. [CrossRef]

74. Pankratov, O.A.; Pakhomov, S.V.; Volkov, B.A. Supersymmetry in heterojunctions: Band-inverting contact on the basis of $\mathrm{Pb}_{1-\mathrm{x}} \mathrm{Sn}_{\mathrm{x}} \mathrm{Te}$ and $\mathrm{Hg}_{1-\mathrm{x}} \mathrm{Cd}_{\mathrm{x}} \mathrm{Te}$. Solid State Commun. 1987, 61, 93-96. [CrossRef]

75. König, M.; Wiedmann, S.; Brüne, C.; Roth, A.; Buhmann, H.; Molenkamp, L.W.; Qi, X.-L.; Zhang, S.-C. Quantum spin Hall insulator state in HgTe quantum wells. Science 2007, 318, 766-770. [CrossRef] [PubMed]

76. Charpentier, S.; Galletti, L.; Kunakova, G.; Arpaia, R.; Song, Y.; Baghdadi, R.; Wang, S.M.; Kalaboukhov, A.; Olsson, E.; Tafuri, F. Induced unconventional superconductivity on the surface states of $\mathrm{Bi}_{2} \mathrm{Te}_{3}$ topological insulator. Nat. Commun. 2017, 8, 2019. [CrossRef] [PubMed]

77. Qu, D.-X.; Teslich, N.E.; Dai, Z.; Chapline, G.F.; Schenkel, T.; Durham, S.R.; Dubois, J. Onset of a two-dimensional superconducting phase in a topological-insulator-Normal-metal $\mathrm{Bi}_{1-\mathrm{x}} \mathrm{Sb}_{\mathrm{x}} / \mathrm{Pt}$ junction fabricated by ion-beam techniques. Phys. Rev. Lett. 2018, 121, 037001. [CrossRef]

78. Li, C.-Z.; Li, C.; Wang, L.-X.; Wang, S.; Liao, Z.-M.; Brinkman, A.; Yu, D.-P. Bulk and surface states carried supercurrent in ballistic $\mathrm{Nb}$-Dirac semimetal $\mathrm{Cd}_{3} \mathrm{As}_{2}$ nanowire-Nb junctions. Phys. Rev. B 2018, 97, 115446. [CrossRef]

79. Schüffelgen, P.; Schmitt, T.; Schleenvoigt, M.; Rosenbach, D.; Perla, P.; Jalil, A.R.; Mussler, G.; Lepsa, M.; Schäpers, T.; Grützmacher, D. Exploiting topological matter for Majorana physics and devices. Solid State Electron. 2019, 155, 99-104. [CrossRef]

80. Kurter, C.; Finck, A.D.K.; Huemiller, E.D.; Medvedeva, J.; Weis, A.; Atkinson, J.M.; Qiu, Y.; Shen, L.; Lee, S.H.; Vojta, T. Conductance spectroscopy of exfoliated thin flakes of $\mathrm{Nb}_{\mathrm{x}} \mathrm{Bi}_{2} \mathrm{Se}_{3}$. Nano Lett. 2019, 19, 38-45. [CrossRef] [PubMed]

81. German, R.; Komleva, E.V.; Stein, P.; Mazurenko, V.G.; Wang, Z.; Streltsov, S.V.; Ando, Y.; Van Loosdrecht, P.H.M. Phonon mode calculations and Raman spectroscopy of the bulk-insulating topological insulator BiSbTeSe 2 . Phys. Rev. Mater. 2019, 3, 054204. [CrossRef]

82. Kayyalha, M.; Kargarian, M.; Kazakov, A.; Miotkowski, I.; Galitski, V.M.; Yakovenko, V.M.; Rokhinson, L.P.; Chen, Y.P. Anomalous low-temperature enhancement of supercurrent in topological-insulator nanoribbon Josephson junctions: Evidence for low-energy Andreev bound states. Phys. Rev. Lett. 2019, 122, 047003. [CrossRef] [PubMed]

83. Miyazaki, A.; Delsolaro, W.V. Determination of the Bardeen-Cooper-Schrieffer material parameters of the HIE-ISOLDE superconducting resonator. Supercond. Sci. Technol. 2019, 32, 025002. [CrossRef]

84. Shearer, C.J.; Slattery, A.D.; Stapleton, A.J.; Shapter, J.G.; Gibson, C.T. Accurate thickness measurement of graphene. Nanotechnology 2016, 27, 125704. [CrossRef] [PubMed]

85. Talantsev, E.F.; Crump, W.P.; Tallon, J.L. Two-band induced superconductivity in single-layer graphene and topological insulator bismuth selenide. Supercond. Sci. Technol. 2018, 31, 015011. [CrossRef]

86. Talantsev, E.F.; Crump, W.P.; Island, J.O.; Xing, Y.; Sun, Y.; Wang, J.; Tallon, J.L. On the origin of critical temperature enhancement in atomically thin superconductors. 2D Mater. 2017, 4, 025072. [CrossRef]

87. Wang, Q.-Y.; Li, Z.; Zhang, W.-H.; Zhang, Z.-C.; Zhang, J.-S.; Li, W.; Ding, H.; Ou, Y.-B.; Deng, P.; Chang, K. Interface-induced high-temperature superconductivity in single unit-cell FeSe films on $\mathrm{SrTiO}_{3}$. Chin. Phys. Lett. 2012, 29, 037402. [CrossRef]

88. Zhang, W.-H.; Sun, Y.; Zhang, J.-S.; Li, F.-S.; Guo, M.-H.; Zhao, Y.-F.; Zhang, H.-M.; Peng, J.-P.; Xing, Y.; Wang, H.-C. Direct observation of high-temperature superconductivity in one-unit-cell FeSe films. Chin. Phys. Lett. 2014, 31, 017401. [CrossRef]

89. Ge, J.F.; Liu, Z.-L.; Liu, C.; Gao, C.-L.; Qian, D.; Xue, Q.-K.; Liu, Y.; Jia, J.-F. Superconductivity above $100 \mathrm{~K}$ in single-layer FeSe films on doped $\mathrm{SrTiO}_{3}$. Nat. Mater. 2015, 14, 285-289. [CrossRef]

90. Zhang, H.-M.; Sun, Y.; Li, W.; Peng, J.-P.; Song, C.-L.; Xing, Y.; Zhang, Q.; Guan, J.; Li, Z.; Zhao, Y. Detection of a superconducting phase in a two-atom layer of hexagonal Ga film grown on semiconducting GaN(0001). Phys. Rev. Lett. 2015, 114, 107003. [CrossRef]

91. Xing, Y.; Zhang, H.-M.; Fu, H.-L.; Liu, H.; Sun, Y.; Peng, J.-P.; Wang, F.; Lin, X.; Ma, X.-C.; Xue, Q.-K. Quantum Griffiths singularity of superconductor-metal transition in Ga thin films. Science 2015, 350, 542-545. [CrossRef] [PubMed]

92. Navarro-Moratalla, E.; Island, J.O.; Manãs-Valero, S.; Pinilla-Cienfuegos, E.; Castellanos-Gomez, A.; Quereda, J.; Rubio-Bollinger, G.; Chirolli, L.; Silva-Guillén, J.A.; Agraï, N. Enhanced superconductivity in atomically thin $\mathrm{TaS}_{2}$. Nat. Commun. 2016, 7, 11043. [CrossRef] [PubMed] 
93. Rhodes, D.; Yuan, N.F.; Jung, Y.; Antony, A.; Hua Wang, H.; Kim, B.; Chiu, Y.-C.; Taniguchi, T.; Watanabe, K.; Barmak, K. Enhanced superconductivity in monolayer $T_{d}$-MoTe 2 with tilted Ising spin texture. arXiv 2019, arXiv:1905.06508.

94. Schüffelgen, P.; Rosenbach, D.; Li, C.; Schmitt, T.; Schleenvoigt, M.; Jalil, A.R.; Kölzer, J.; Wang, M.; Bennemann, B.; Parlak, U. Boosting transparency in topological Josephson junctions via stencil lithography. arXiv 2018, arXiv:1711.01665.

95. Han, Z.; Allain, A.; Arjmandi-Tash, H.; Tikhonov, K.; Feigel'man, M.; Sacépé, B.; Bouchiat, V. Collapse of superconductivity in a hybrid tin-graphene Josephson junction array. Nat. Phys. 2014, 10, 380-386. [CrossRef]

96. Gross, F.; Chandrasekhar, B.S.; Einzel, D.; Andres, K.; Hirschfeld, P.J.; Ott, H.R.; Beuers, J.; Fisk, Z.; Smith, J.L. Anomalous temperature dependence of the magnetic field penetration depth in superconducting $\mathrm{UBe}_{13}$. Z. Phys. B Condens. Matter 1986, 64, 175-188. [CrossRef]

97. Gorter, C.J.; Casimir, H. On supraconductivity I. Physica 1934, 1, 306-320. [CrossRef]

98. Poole, P.P.; Farach, H.A.; Creswick, R.J.; Prozorov, R. Superconductivity, 2nd ed.; Associated Press: London, UK, 2007; pp. 52-55.

99. Talantsev, E.F.; Crump, W.P.; Storey, J.G.; Tallon, J.L. London penetration depth and thermal fluctuations in the sulphur hydride $203 \mathrm{~K}$ superconductor. Ann. Phys. 2017, 529, 1600390. [CrossRef]

100. Mozaffari, S.; Balicas, L.; Minkov, V.S.; Knyazev, D.; Eremets, M.I.; Einaga, M.; Shimizu, K.; Sun, D.; Balakirev, F.F. Superconducting Hydride under Extreme Field and Pressure; LA-UR-18-30460; Los Alamos National Laboratory: Los Alamos, NM, USA, 2019.

101. Pal, B.; Joshi, B.P.; Chakraborti, H.; Jain, A.K.; Barick, B.K.; Ghosh, K.; Bhunia, S.; Laha, A.; Dhar, S.; Gupta, K.D. Experimental evidence of a very thin superconducting layer in epitaxial indium nitride. Supercond. Sci. Technol. 2019, 32, 015009. [CrossRef]

102. Jones, C.K.; Hulm, J.K.; Chandrasekhar, B.S. Upper critical field of solid solution alloys of the transition elements. Rev. Mod. Phys. 1964, 36, 74-76. [CrossRef]

103. Helfand, E.; Werthamer, N.R. Temperature and purity dependence of the superconducting critical field, $H_{\mathrm{c} 2}$. II. Phys. Rev. 1966, 147, 288-294. [CrossRef]

104. Werthamer, N.R.; Helfand, E.; Hohenberg, P.C. Temperature and purity dependence of the superconducting critical field, $H_{\mathrm{c} 2}$. III. Electron spin and spin-orbit effects. Phys. Rev. 1966, 147, 295-302. [CrossRef]

105. Baumgartner, T.; Eisterer, M.; Weber, H.W.; Fluekiger, R.; Scheuerlein, C.; Bottura, L. Effects of neutron irradiation on pinning force scaling in state-of-the-art $\mathrm{Nb}_{3} \mathrm{Sn}$ wires. Supercond. Sci. Technol. 2014, 27, 015005. [CrossRef]

106. Gor'kov, L.P. The critical supercooling field in superconductivity theory. Sov. Phys. JETP 1960, 10, 593-599.

107. Suhl, H.; Matthias, B.T.; Walker, L.R. Bardeen-Cooper-Schrieffer theory of superconductivity in the case of overlapping bands. Phys. Rev. Lett. 1959, 3, 552-554. [CrossRef]

108. Nagamatsu, J.; Nakagawa, N.; Muranaka, T.; Zenitani, Y.; Akimitsu, J. Superconductivity at $39 \mathrm{~K}$ in magnesium diboride. Nature 2001, 410, 63-64. [CrossRef]

109. Kamihara, Y.; Hiramatsu, H.; Hirano, M.; Kawamura, R.; Yanagi, H.; Kamiya, T.; Hosono, H. Iron-based layered superconductor: LaOFeP. J. Am. Chem. Soc. 2006, 128, 10012-10013. [CrossRef]

110. Buzea, C.; Yamashita, T. Review of the superconducting properties of $\mathrm{MgB}_{2}$. Supercond. Sci. Technol. 2001, 14, R115-R146. [CrossRef]

111. Zehetmayer, M. A review of two-band superconductivity: Materials and effects on the thermodynamic and reversible mixed-state properties. Supercond. Sci. Technol. 2013, 26, 043001. [CrossRef]

112. Hänisch, J.; Iida, K.; Hühne, R.; C Tarantini, C. Fe-based superconducting thin films-preparation and tuning of superconducting properties. Supercond. Sci. Technol. 2019, 32, 093001. [CrossRef]

113. Shalnikov, A. Superconducting thin films. Nature 1938, 132, 74. [CrossRef]

114. Cohen, R.W.; Abeles, B. Superconductivity in granular aluminum films. Phys. Rev. 1968, 168, $444-450$. [CrossRef]

115. Pracht, U.S.; Bachar, N.; Benfatto, L.; Deutscher, G.; Farber, E.; Dressel, M.; Scheffler, M. Enhanced Cooper pairing versus suppressed phase coherence shaping the superconducting dome in coupled aluminum nanograins. Phys. Rev. B 2016, 93, 100503(R). [CrossRef] 
116. Pracht, U.S.; Cea, T.; Bachar, N.; Deutscher, G.; Farber, E.; Dressel, M.; Scheffler, M.; Castellani, C.; García-García, A.M.; Benfatto, L. Optical signatures of the superconducting Goldstone mode in granular aluminum: Experiments and theory. Phys. Rev. B 2017, 96, 094514. [CrossRef]

117. Eilenberger, G. Transformation of Gorkov's equation for type II superconductors into transport-like equations. Z. Phys. 1968, 214, 195-213. [CrossRef]

118. Usadel, K.D. Generalized diffusion equation for superconducting alloys. Phys. Rev. Lett. 1970, 25, 507-509. [CrossRef]

119. Rusanov, A.Y.; Hesselberth, M.B.S.; Aarts, J. Depairing currents in superconducting films of $\mathrm{Nb}$ and amorphous MoGe. Phys. Rev. B 2004, 70, 024510. [CrossRef]

120. Sasaki, S.; Segawa, K.; Ando, Y. Superconductor derived from a topological insulator heterostructure. Phys. Rev. B 2014, 90, 220504. [CrossRef]

121. Andersen, L.; Wang, Z.; Lorenz, T.; Ando, Y. Nematic superconductivity in $\mathrm{Cu}_{1.5}(\mathrm{PbSe})_{5}\left(\mathrm{Bi}_{2} \mathrm{Se}_{3}\right)_{6}$. Phys. Rev. B 2018, 98, 220512(R). [CrossRef]

122. Reyren, N.; Thiel, S.; Caviglia, A.D.; Fitting Kourkoutis, L.; Hammerl, G.; Richter, C.; Schneider, C.W.; Kopp, T.; Rüetschi, A.-S.; Jaccard, D. Superconducting interfaces between insulating oxides. Science 2007, 317, 1196-1199. [CrossRef]

123. Gozar, A.; Logvenov, G.; Fitting Kourkoutis, L.; Bollinger, A.T.; Giannuzzi, L.A.; Muller, D.A.; Bozovic, I. High-temperature interface superconductivity between metallic and insulating copper oxides. Nature 2008, 455, 782-785. [CrossRef] [PubMed]

124. Campi, G.; Bianconi, A.; Poccia, N.; Bianconi, G.; Barba, L.; Arrighetti, G.; Innocenti, D.; Karpinski, J.; Zhigadlo, N.D.; Kazakov, S.M. Inhomogeneity of charge-density-wave order and quenched disorder in a high- $T_{\mathrm{c}}$ superconductor. Nature 2015, 525, 359-362. [CrossRef] [PubMed]

125. Ricci, A.; Poccia, N.; Joseph, B.; Innocenti, D.; Campi, G.; Zozulya, A.; Westermeier, F.; Schavkan, A.; Coneri, F.; Bianconi, A. Direct observation of nanoscale interface phase in the superconducting chalcogenide $\mathrm{K}_{\mathrm{x}} \mathrm{Fe}_{2-\mathrm{y}} \mathrm{Se}_{2}$ with intrinsic phase separation. Phys. Rev. B 2015, 91, 020503. [CrossRef]

(C) 2019 by the author. Licensee MDPI, Basel, Switzerland. This article is an open access article distributed under the terms and conditions of the Creative Commons Attribution (CC BY) license (http://creativecommons.org/licenses/by/4.0/). 